\title{
Establishing the risk denominator in a Sharpe ratio framework for share selection from a momentum investment strategy approach
}

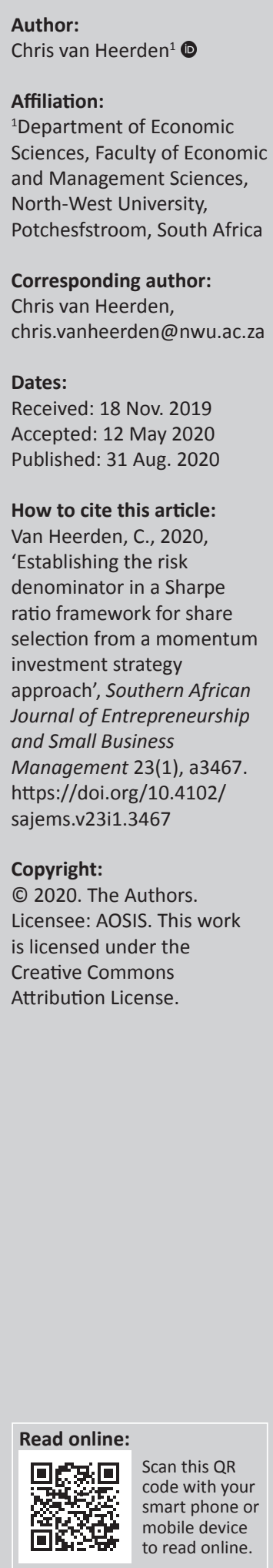

Background: Based on the static mean-variance portfolio optimisation theory, investors will choose the portfolio with the highest Sharpe ratio to achieve a higher expected utility. However, the traditional Sharpe ratio only accounts for the first two moments of return distributions, which can lead to false portfolio performance diagnostics with the presence of asymmetric, highly skewed returns.

Aim: With many criticising the standard deviation's applicability and with no consensus on the ascendency of which other risk denominator to consult, this study contributes to the literature by validating the importance of consulting value-at-risk as the more commendable risk denominators for the Johannesburg Stock Exchange.

Method: These results were derived from a novel index approach that produces a comprehensive risk-adjusted performance evaluation score.

Results: Of the 24 Sharpe ratio variations under evaluation, this study identified the value-at-risk Sharpe ratio as the better variation, which led to more profitable share selections for long-only portfolios from a one-year and five-year momentum investment strategy perspective. However, the attributes of adjusting for skewness and kurtosis exhibited more promise from a three-year momentum investment strategy perspective.

Conclusion: The results highlighted the ability to outperform the market, which further emphasised the importance of active portfolio management. However, the results also confirmed that active and more passive equity portfolio managers will have to consult different Sharpe ratio variations to enhance the ability to outperform the market and a buy-and-hold strategy.

Keywords: Admissible risk denominator; JSE; momentum investment strategy; risk-adjusted performance; shares; Sharpe ratio; South Africa.

\section{Introduction}

Common practice in selecting suitable portfolio compositions comprises the characterising of the different assets under consideration, where the desired properties in terms of reward and risk are evaluated (Markowitz 1952). Based on modern portfolio theory, these properties are generally identified with the mean and variance of returns. However, Roy (1952) considered the implications of minimising the upper bound of the chance of losses, if information is confined to only the first and second order moments. This implies that investors tend to be more protective of portfolio wealth against the possibility of making losses and not necessarily interested in how share prices deviate around a profitable mean. From this argument Markowitz (1959) was inspired to introduce the downside risk measure, named semi-variance, thus replacing the ordinary variance to include a downside risk measure for the first time in portfolio selection. Also, as investors' attitude towards risk can vary considerably, this led some studies to consider different $n$th moments of downside to suit different preferences, thus leading to the introduction of the lower partial moment (LPM) of the downside (Bawa 1975; Fishburn 1977). Nonetheless, the theory of portfolio analysis was still assumed to be essentially normative by many, which led some studies to continue measuring risk on the basis of variance, through the application of the standard deviation as the denominator of the Sharpe ratio (Sharpe 1966). Over time many criticised this denominator, as it measures only the dispersion of returns around its historical average and penalises positive and negative deviations from the historical average in a similar manner, leading thus to a misperception of actual risk (e.g. Harlow 1991; Lhabitant 2004). This implies that the standard deviation does not differentiate between downside and upside risk (De Wet et al. 2008; Harding 2002), especially 
if the divergence from normality becomes more apparent when the higher moments (skewness and kurtosis) of the return distributions are taken into account (Kat 2003). This can pose a problem when investing in emerging markets, such as the Johannesburg Stock Exchange (JSE), where the presence of higher moments has been established (Bekaert et al. 1998; Van Heerden 2015). These findings, therefore, imply that the traditional Sharpe ratio will find it difficult to rank volatile returns (Lo 2002), due to its risk denominator, and will thus fail to capture downside surprises (Lamm 2003). With this outcome rendering the creditability of the traditional Sharpe ratio inconsequential, it opens the field of performance measurement to establish solutions to overcome the limitations posed by the standard deviation.

The presence of higher moments can be considered as an eminent hurdle that has hindered the field of performance measurement for decades. The study of Mandelbrot (1963) was one of the first to suggest that asset return distributions can be 'fat-tailed', implying that outliers will be more numerous than would be expected from a Gaussian distribution. Fama (1965a) accentuated this argument when he directed the focus to stable Paretian distributions, which led other studies (e.g. Fama 1965b) to advocate the mean absolute deviation as the more preferred risk measure to adopt. However, findings from Wise (1966) and Sharpe (1971) suggest otherwise, emphasising that the choice of the appropriate risk measure might be far from obvious. Later studies by Sinn (1983) and Meyer (1987) argue that investment funds' returns are equal in distribution to one another, with the exception of the location and scale (LS) property. However, Schuhmacher and Eling (2011) are in disagreement with this argument, reporting that several distribution types can have the tendency to satisfy the LS property. This explains the possibility of high-ranking correlations between different riskadjusted performance measures, where different risk measures are adopted (Eling et al. 2010; Schuhmacher \& Eling 2012).

Overall, the findings above raise the question as to whether it matters which risk denominator can be considered admissible for the Sharpe ratio framework (where the latter refers to the following equation: Excess returns $\div$ Risk denominator) and to what extent portfolio performance can be influenced by this choice. The literature argues that admissible risk measures should satisfy positive homogeneity and that adding a positive constant (risk-free rate) to an investment fund's random excess returns should not increase the investment fund's risk. Nevertheless, regarding the latter, the presence of heightened risk levels has been acknowledged with the adding of risk-free rate proxies (Schuhmacher \& Eling 2012), especially from a South African perspective (e.g. Grandes \& Pinaud 2004). Although this still remains a limitation in the literature, this study attempted to address the issue by including a riskfree rate proxy that has exhibited the lowest return volatility (see Van Heerden 2016). Furthermore, it is argued that the combination of investment funds and risk-free rates can still satisfy the LS property, but not necessarily when combining different investment funds (Meyer \& Rasche 1992), where stronger conditions on distributions are required (e.g. Chen et al. 2011). However, for distributions to satisfy the LS property the third and fourth normalised order moment should be identical, except under the generalised LS property (e.g. Meyer \& Rasche 1992). This is, however, not the case for emerging market returns (Van Heerden 2015), which can lead to very different portfolio allocations when comparing the traditional mean-variance framework to more advanced performance measures (e.g. Fung \& Hsieh 1999; Terhaar et al. 2003). The study of Gilli and Schumann (2011) further argues that alternative, nonGaussian specifications, such as conditional and partial moments, quantiles and drawdowns may be more applicable in these instances. The literature, however, still fails to produce a risk denominator that can also account for risks, such as callable risk, liquidity risk or discounting factors, such as tax implications and other opportunity costs. Essentially, as the traditional Sharpe ratio is only valid for Gaussian distributions or quadratic preferences (Ziemba 2005), the findings cited above provide a decisiontheoretic foundation for evaluating the application of already established risk denominator alternatives for the standard deviation, such as the tracking error, maximum drawdown, LPMs, downside potential and value-at-risk (VaR) based risk measures, to name a few.

The inability of the literature to reach a consensus on which risk denominator is more commendable to incorporate in the Sharpe ratio framework provided the inspiration for this study. The selection of 24 Sharpe ratio variations were based on the unique perspective each provided by means of its risk denominator or the adjustment feature it offered. The approach of this article was also motivated by the study of Jegadeesh and Titman (1993), who argued that past 'winners' on average tend to outperform past 'losers', which implies that there is momentum in share returns, to some extent, which can be exploited as documented by Fama (1991). This led this study to adopt a novel approach of applying risk-adjusted ratios as a forecasting tool to select shares, and to identify the ratio with the ability to identify portfolio compositions that will yield the highest future riskadjusted performance. For this study this implies that the year-end rankings of each of the 24 Sharpe ratio variations under evaluation at time $t$ will be used to determine the share selections for each representing portfolio over one, three and five years (ex post, in-sample), whereafter the portfolios will be rebalanced according to a new set of rankings. These portfolios will be compiled from an investment universe of 583 listed and 357 delisted South African shares. Each equally weighted, long-only equity portfolio will comprise 40 shares that exhibited fairly low volatility (standard deviation), ranging between $0 \%$ and $1.68 \%$ over the different portfolios and investment horizons under evaluation. After each consecutive rebalancing year (time $t+1, t+3$ and $t+5$ ) the Sharpe ratio variation that led to the best-performing portfolio (based on in-sample, ex post performance) will be identified. Each equity portfolio's ability to outperform 
a buy-and-hold strategy on the equity, bond and money market will also be evaluated. Two equity market proxies (JSE Top 40 and JSE All Share indices), two bond index proxies (1-3-year and 3-7-year bond indices) and one money market index proxy (12-month JIBAR yield rate) will be utilised. The overall outperformance evaluation will be conducted through an index ranking approach. Two sets of index rankings will be consulted to derive a final conclusion. The first ranking set (equally weighted) will assign the same weight to seven categories, which will entail geometric returns, upside potential, downside potential, standard deviation, maximum downturn, upside risk, and downside risk. The second ranking set (50:50 weighting) will assign $25 \%$ to geometric returns and upside potential and will divide the remaining $50 \%$ evenly between the risk measures, namely downside potential, standard deviation, maximum downturn, upside risk and downside risk. The motive for this index ranking approach is to introduce an innovative risk-adjusted performance method that can be used to evaluate equity portfolios more comprehensively, especially if selected shares exhibit both normal and non-normal return distributions.

The scope of this study will, however, not include a comparison study of alternative momentum investment strategies, as it will only focus on renewing the creditability of the Sharpe ratio (or variations thereof) as a future share selecting tool from a momentum investment strategy perspective. Also, the rebalancing approach of this study will not adopt any unique mean-variance optimisation approach, as rebalancing was only based on the new set of rankings provided by the 24 Sharpe ratio variations, every one, three and five years. This study will also exclude short-selling and the use of derivatives. Moreover, the effects of transaction costs and taxes will be ignored, although the share returns were adjusted for splits and dividends. To achieve this goal this study commences by elaborating on the evolution of the Sharpe ratio and the admissible risk measure, which will be followed by an overview of the method and data utilised. The empirical results are then reported, followed by concluding remarks and recommendations.

\section{The evolution of the Sharpe ratio and the admissible risk measure}

To understand the origins of the traditional Sharpe ratio, it is important to acknowledge the link between the standard expected utility theory framework, the meanvariance optimisation framework, and the reasoning behind the formation of the traditional Sharpe ratio. Suppose an investor desires to allocate his wealth between a risky and risk-free asset, where the returns on these assets over time interval $\Delta t$ can be illustrated as follows (Zakamouline \& Koekebakker 2009):

$x=\mu_{x}+\sigma_{x} \varepsilon=\mu \Delta t+\sigma \sqrt[2]{\Delta t} \varepsilon$

[Eqn 1]

$r_{f}=r \Delta t$

[Eqn 2]
In Equation 1, $\mu$ denotes the mean and $\sigma$ the standard deviation of the risky asset returns per unit of time; $\varepsilon$ denotes a normalised stochastic variable, such that $E[\varepsilon]=0$ and $\operatorname{Var}[\varepsilon]=1$. In Equation 2, $r$ denotes the risk-free rate per unit of time. Furthermore, assume that the investor possesses the wealth of $w$ and decides to invests $a$ in the risky assets and $(w-a)$ in the risk-free assets. This implies that the investor's wealth and expected utility over time interval $\Delta t$ can be illustrated as follows (Zakamouline \& Koekebakker 2009):

$\tilde{w}=a\left(x-r_{f}\right)+w\left(1+r_{f}\right)$

[Eqn 3]

$E[U(\tilde{w})]=E\left[U\left(a\left(x-r_{f}\right)+w\left(1+r_{f}\right)\right)\right]$

[Eqn 4]

For a given utility function $U(\cdot)$, and by assuming it increases concave and is a differential function, the investor's objective to maximise his expected utility by investing in $a$ can be illustrated as follows (Zakamouline \& Koekebakker 2009):

$E\left[U^{*}(\tilde{w})\right]=\max _{a} E[U(\tilde{w})]$

However, if the investor decides to invest in several different risky assets, the mean-variance framework must be implemented to derive the most efficient portfolio that optimises the expected utility. In this instance, suppose the amounts $a_{0, t}, a_{1, t}, \ldots, a_{n, t}$ are invested at time $t$ in the different assets $i=0,1, \ldots, n$, where 0 denotes the risk-free asset. If the value of the portfolio at time $t$ is $w_{t}=a_{0, t}+\ldots+a_{n, t}$, then its future value is equal to $w_{t+1}=a_{0, t}\left(1+r_{t}\right)+\sum_{i=1}^{n} a_{i, t} p_{i, t+1} / p_{i, t}$ where $r_{t}$ is the risk-free rate at horizon one and $p_{i, t}$ is the unitary price at time $t$ of asset $i$. With the selection of the portfolio allocation, the investor must solve the following optimisation problem from the mean-variance framework (Darolles \& Gourieroux 2010):

$\max _{a_{0, t}, \ldots, a_{n, t}} E_{t}\left[w_{t+1}\right]-\frac{A}{2} V_{t}\left[w_{t+1}\right]$, s.t. $\sum_{i=0}^{n} a_{i, t}=w_{t}$

[Eqn 6]

In Equation 6, $A$ denotes the individual (absolute) risk aversion, $E_{t}$ denotes the expectation and $V_{t}$ denotes the variance, given the available information utilised by the investor at time $t$. By solving the budget constraint, the quantity invested in the risk-free asset can be obtained as $a_{0, t}=w_{t}-\sum_{i=1}^{n} a_{i, t}$. By substitution, the unconstrained quadratic optimisation problem is deduced to be the following (Darolles \& Gourieroux 2010):

$$
\max _{a_{1, t}, \ldots, a_{n, t}} w_{t}\left(1+r_{t}\right)+E_{t}\left[\sum_{i=1}^{n} a_{i, t} y_{i, t+1}\right]-\frac{A}{2} V_{t}\left[\sum_{i=1}^{n} a_{i, t} y_{i, t+1}\right]
$$

[Eqn 7]

In Equation $7, y_{i, t+1}=\left(p_{i, t+1}-p_{i, t}\right) / p_{i, t}-r_{t}$. The optimal allocation in the risky assets, $a_{t}^{*}=\left(a_{1, t}^{*}, \ldots, a_{n, t}^{*}\right)$, can then be illustrated by (Markowitz 1952):

$a_{t}^{*}=\frac{1}{A} \sum_{t}^{-1} m_{t}$

[Eqn 8] 
In Equation 8, $m_{t}$ is the expectation of the vector of excess returns $y_{t+1}=\left(y_{1, t+1}, \ldots, y_{n, t+1}\right)^{\prime}$. Furthermore, the optimal value of the objection function is equal to (Darolles \& Gourieroux 2010):

$$
\prod_{t}=w_{t}\left(1+r_{t}\right)+\frac{1}{2 A} m_{t}^{\prime} \sum_{t}^{-1} m_{t}
$$

Evidently, it depends on the risk-free rate, the initial budget, the risk-aversion coefficient and quantity, $S_{t: 1, \ldots, n}=m_{t}^{\prime} \sum_{t}^{-1} m_{t}$, which summarises the stochastic properties of the risky asset returns (Treynor 1965; Sharpe 1966). The above mentioned quantity is called the Sharpe performance of the set of assets $1, \ldots, n$ at time $t$, which also depends on the information utilised by the investor to compute the variances, covariances and means. To simplify the Sharpe performance illustration, consider only a portfolio that includes a single risky asset $j$ and a risk-free asset (Darolles \& Gourieroux 2010):

$S_{t: j}=\frac{m_{j, t}^{2}}{\sigma_{j, t}^{2}}$

In Equation 10, $m_{j, t}^{2}$ is the expected excess returns between the risky asset $j$ and the risk-free asset, and $\sigma_{j, t}^{2}$ denotes the variance of risky asset $j$. This Sharpe performance measure can take on any positive value; however, it can also be computed by taking the sign of the expected excess returns into account, as $S_{t: j}=m_{j, t} / \sigma_{j, t}$ (e.g. McLeod \& Van Vuuren 2004). Nonetheless, in a scenario where the investor has to choose between two competing portfolios - where the first portfolio includes a risk-free asset and the risky asset $j$, and the second portfolio includes a risk-free asset and the risky asset $b$ - the portfolio with the highest Sharpe performance will always be chosen, as it implies a higher risk-adjusted return. By redefining this performance measure as $S_{t: j}^{1 / 2}=\left|m_{j, t}\right| / \sigma_{j, t}$ and by annualising the expected excess returns and volatility, this measure also corresponds to the renowned Sharpe ratio or the reward-to-variability ratio, as originally published (Sharpe 1966).

The Sharpe ratio was introduced as an extension of Treynor's (1965) work. The reward-to-volatility ratio or Treynor ratio (Treynor 1965) makes use of systematic risk (beta) as the risk denominator (adapted from Treynor 1965):

$T=\frac{r_{p}-r_{f}}{\beta}$

[Eqn 11]

In Equation 11, $r_{p}$ denotes the return of a security, $r_{f}$ denotes the risk-free rate and $\beta$ denotes market risk. Unfortunately, the literature has reported several empirical failures of beta. For example, the market proxy used in the estimation of beta must be as comprehensive as possible in representing the entire market under evaluation. Other factors such as beta instability, its failure to explain share return behaviour, regression biasness and thin-trading (e.g. Blume 1975; Bradfield 2015; Fama \& French 1992) also caused many to criticise its viability. Another critical flaw of the Treynor ratio is that it assumes portfolios are already completely diversified
(Treynor 1965), thus ignoring company-specific risk (unsystematic risk). This limitation led to the development of the Sharpe ratio, which utilises total risk (the standard deviation) that will penalise the lack of diversification. Although the Sharpe ratio was initially intended to serve as an ex ante performance measure, it is generally utilised in an ex post manner. Even so, Sharpe (1994) argues that historical results are assumed to have some predictive ability, but he acknowledges the fact that the use of ex post Sharpe ratios as substitutes for unbiased predictions of ex ante ratios is still subject to future deliberations. It is also further argued that both the ex ante and ex post Sharpe ratios fail to account for the correlation of a fund or strategy, rendering it lacking and demanding augmentation in certain instances (Sharpe 1994). The study of Dowd $(1999,2000)$ attempted to address some of these issues, proposing a generalised rule that can overcome the problem of correlation with the standard application of the Sharpe ratio. He argues that the choice of incorporating an additional asset in an existing portfolio can be evaluated by computing a Sharpe ratio for both the existing $\left(S R^{\text {old }}\right)$ and the new portfolio $\left(S R^{\text {new }}\right)$, where the new portfolio includes the additional asset. As the comparison between the two Sharpe ratios already accounts for the correlation present, the final choice only resides on whether the new asset will raise the Sharpe ratio of the existing portfolio. Thus, the inclusion of the new asset will only be considered if $S R^{\text {old }}$ is less than $S R^{\text {new }}$. In addition, Dowd $(1999,2000)$ also recommends the substitution of the standard deviation with the VaR measure (see Equation 12), which offers the Sharpe ratio the ability to limit the distortion in investment decision-making as correlation in returns escalates:

VaR - Sharpe ratio $=\frac{r_{p}-r_{f}}{\operatorname{VaR}}$

[Eqn 12]

In Equation 12, $r_{p}$ denotes the annualised return of the share under evaluation, $r_{f}$ denotes the annualised risk-free rate, $\left(r_{p}-r_{f}\right)$ denotes the excess returns and $V a R=r_{p}+z_{c} \times \sigma$, with $z_{c}$ as the critical value for probability $(1-\alpha)=-2.326$, for $\alpha=99 \%$ probability in this study, and $\sigma$ is the annualised standard deviation of the returns. However, a major downfall of the VaR approach is that it is still based on the meanvariance framework, thus assuming the presence of a Gaussian distribution, and unable to account for higher moments. The VaR, therefore, fails to provide any information on the shape of the distribution's tail and on the expected size of loss beyond the decided confidence level, which is referred to as tail risk (CGFS 1999, 2000). Moreover, the studies of Goetzmann et al. (2002) and Agarwal and Naik (2004) acknowledge the presence of significant left-tail risk with hedge funds, which exhibit non-normal pay-offs due to the application of options and option-like dynamic trading strategies. This implies that the traditional Sharpe ratio may be open to manipulation, which encouraged Goetzmann et al. to derive general conditions and dynamic and static rules in order to maximise the expected Sharpe ratio with the utilisation of derivative instruments. However, earlier studies by Artzner et al. $(1997,1999)$ propose the use of the expected 
shortfall, which is the conditional expectation of loss (CVaR). Substituting the standard deviation with the CVaR enables the Sharpe ratio to account for the possible loss beyond the normal VaR level (e.g. Esfahanipour \& Mousavi 2011):

Conditional $(C V a R)$ Sharpe ratio $=\frac{r_{p}-r_{f}}{C V a R}$

In Equation 13, $r_{p}$ denotes the annualised return of the share under evaluation, $r_{f}$ denotes the annualised risk-free rate, $C V a R=\mathrm{r}_{\mathrm{p}}+(-\sigma / \sqrt[2]{2 \pi})\left[\exp \left(-0.5\left(\left(z_{c} \times \sigma\right) / \sigma\right)^{2}\right)\right] /(1-\alpha)$, with $z_{c}$ as the critical value for probability $(1-\alpha)=-2.326$, for $\alpha=99 \%$ probability in this study, and $\sigma$ is the annualised standard deviation of the returns. This admissible risk alternative demonstrated attractive properties for portfolio decision-making (e.g. Agarwal \& Naik 2004; Esfahanipour \& Mousavi 2011; Tasche 2002), but due to its dependency on sample size (e.g. Yamai \& Yoshiba 2002), inability to generate more stable statistical estimates compared to the normal VaR and relative poor out-of-sample performance if tails are not modelled correctly (Sarykalin et al. 2008), other studies sought to identify alternative risk denominators. One proposal entailed the implementation of the Cornish-Fisher expansion (e.g. Favre \& Galeano 2002) to adjust the normal VaR to account for higher moments, which led to the development of the modified $\operatorname{VaR}(M V a R)$ that can be utilised as an alternative risk denominator for the Sharpe ratio as follows (e.g. Gregoriou \& Gueyie 2003):

Modified $($ MVaR $)$ Sharpe ratio $=\frac{r_{p}-r_{f}}{M V a R}$

[Eqn 14]

In Equation 14, $r_{p}$ denotes the annualised return of the share under evaluation, $r_{f}$ denotes the annualised risk-free rate, $M V a R=\mathrm{r}_{\mathrm{p}}+\sigma^{2}\left[z_{c}+S\left(z_{c}^{2}-1\right) / 6+K\left(z_{c}^{3}-3 z_{c}\right) / 24-S^{2}\left(2 z_{c}^{3}-5 z_{c}\right) / 36\right]$, with $z_{c}$ as the critical value for probability $(1-\alpha)=-2.326$, for $\alpha=99 \%$ probability in this study, $\sigma^{2}$ is the annualised variance of the returns, $S$ is the skewness and $K$ denotes the kurtosis.

In addition to the recommendation of utilising a VaR-based risk denominator to eliminate correlation, as discussed above, the study of Lo (2002) presented an alternative approach. He derived explicit expressions for the statistical distribution of the Sharpe ratio by applying standard asymptotic theory, in an attempt to improve the accuracy of the traditional Sharpe ratio. In the process, Lo (2002) proved that monthly Sharpe ratios cannot be annualised by multiplying by $\sqrt[2]{12}$, except under certain circumstances. He further proposed an alternative method for the conversion of stationary returns, where the Sharpe ratio can be adjusted for serial correlation (SC) as follows (Lo 2002):

$$
\eta(q) S R=\frac{q}{\sqrt[2]{q+2 \sum_{k=1}^{q-1}(q-k) \rho_{\mathrm{k}}}}
$$

In Equation 15, $S R$ denotes the traditional Sharpe ratio estimate on a monthly basis, $q=12$ and $\rho_{k}$ is the $k$ th autocorrelation for returns. Results from the study of
Lo (2002) illustrated that Sharpe ratios, especially for hedge funds, can be overestimated by as much as $65 \%$, thereby accentuating the need to adjust for SC in monthly returns. From a different perspective, Černý (2002) argued that the traditional Sharpe ratio is closely related to quadratic utility and extended the definition of the Sharpe ratio to an entire family of constant relative risk-aversion utility functions, which restated the equilibrium restrictions of the generalised Sharpe ratios, as originally published by Dowd (1999). This renewed generalised Sharpe ratio exhibited more consistent performance rankings for different investment opportunities, even with the presence of non-normal returns (Černý 2002). However, Harding (2002) addressed the limitations posed by non-normal returns differently. He claims that risk is not always a meaningful and observable quantity, which implies that the creditability of the standard deviation depends on the ability to compute it from a stationary and parametric process, which is not always possible with the presence of non-normal returns. This argument implies that the earlier suggestion by Markowitz (1959) must be revised, where the favourable attributes of the semi-variance, as a downside risk measure, must be re-established for portfolio selection purposes. Harding's statement builds on an earlier study of Sortino and Van der Meer (1991), where the LPM of the second order is utilised as a risk denominator alternative (see Equation 16). Later on, the study of Kaplan and Knowles (2004) further extended the application of LPMs as risk denominators, where Sortino and Van der Meer's downside risk measure was augmented by the validation of LPMs of the third order, which led to the development of the Kappa 3 ratio (see Equation 17):

$$
\begin{gathered}
\text { Sortino ratio }=\frac{r_{p}-r_{f}}{\sqrt[2]{L P M_{2}(\tau)}} \\
\text { Kappa } 3 \text { ratio }=\frac{r_{p}-r_{f}}{\sqrt[3]{L P M_{3}(\tau)}}
\end{gathered}
$$

In Equation 16 and Equation 17, $r_{p}$ denotes the annualised return of the share under evaluation, $r_{f}$ denotes the annualised risk-free rate, $L P M_{n p}(\tau)=\frac{1}{T} \sum_{t=1}^{T} \max \left[\tau-r_{p t}, 0\right]^{n}$, where $\tau$ is the minimal acceptable return $\left(r_{p}=0\right.$ will be adopted as $\tau$ in this study), and $n$ represents the chosen order of the LPMs. The downside deviation of the order $n\left(\sqrt[n]{L P M_{n}(\tau)}\right)$ substitutes the standard deviation as an admissible risk denominator, which accentuates the behaviour framework of Kahneman and Tversky's (1979) loss aversion preferences and the axiomatic approach of Gul's (1991) disappointment aversion preferences, where a greater weight is assigned to losses relative to gains. In contrast, the study of Young (1991) argued that the maximum loss of capital over a specified period (maximum drawdown) may be more insightful as a LPM risk denominator, which led to the introduction of the Calmar ratio (see Equation 18). The maximum drawdown (MD) represents the maximum loss an investor can suffer when buying at the highest point and selling at the lowest following trough. This admissible risk denominator's 
attributes also inspired an array of different variations of the Calmar ratio, including the Burke ratio (Burke 1994), the Sterling ratio (Kestner 1996; adjusted to the Sharpe ratio framework, see e.g. Bacon 2008; Kolbadi \& Ahmadinia 2011), the Martin ratio or Ulcer performance index (Martin \& McCann 1998) and the Pain ratio (Zephyr Association 2006):

Calmar ratio $=\frac{r_{p}-r_{f}}{M D}$

Burke ratio $=\frac{r_{p}-r_{f}}{\sqrt[2]{\sum_{j=1}^{j=d} D_{j}^{2}}}$

Sterling ratio $=\frac{r_{p}-r_{f}}{\left|\sum_{j=1}^{j=d} \frac{D_{j}}{d}\right|}$

Martin ratio $=\frac{r_{p}-r_{f}}{\sqrt[2]{\sum_{j=1}^{j=d} \frac{D_{j}^{2}}{n}}}$

Pain ratio $=\frac{r_{p}-r_{f}}{\sum_{j=1}^{j=d} \frac{D_{j}}{n}}$

[Eqn 22]

In Equations 18-22, $r_{p}$ denotes the annualised return of the share, $r_{f}$ denotes the annualised risk-free rate, $M D$ denotes the maximum drawdown that is the maximum cumulative loss between a peak and a following trough, where $M D=\underset{u \in[0, t]}{\max }[P(u)-T(u)]$, with $t$ denoting the number of return observations, $P(u)$ denoting the return value at the peak over the interval of size $t$, and $T(u)$ denoting the return value of the following trough over the interval of size $t, D_{j}$ denotes the drawdown since the previous peak in period $j$, denominator $d$ denotes the fixed number of observations as preferred by the investor (in this study it will be the actual number of drawdowns) and $n$ denotes the duration of a drawdown. By incorporating the duration of drawdowns, as originally introduced by the Ulcer index (Martin \& McCann 1989), the Martin and Pain ratios are able to penalise managers that take too long to recover to previous highs. Although the Martin and Pain ratios can be sensitive to the frequency of the time period under evaluation, the incorporation of both the duration and depth of the drawdowns in the performance measurement process provides a unique risk perspective that other risk-adjusted performance ratios tend to overlook. In addition, the Burk ratio also utilises the square root of the sum of the squares of each drawdown in order to penalise major drawdowns relative to less significant occurrences. Introducing another unconventional risk perspective is the original Sterling ratio (Kestner 1996), which suggests the use of the average largest drawdown plus $10 \%$ as the admissible risk denominator. The additional $10 \%$ is intended for arbitrary compensation, as the average largest drawdown tends to be smaller than the maximum drawdown. However, by excluding the $10 \%$ and by converting the original Sterling ratio to a Sharpe ratio framework, as suggested by Bacon (2008), the substitution of the denominator with the fixed term $d$ imposes a more restricted performance measurement. This entails that the average of only a fixed number of the largest drawdowns is adopted as the admissible risk denominator.

Besides the modification suggested for the original Sterling ratio, Bacon (2008) also proposed several composite indicators that can serve as additional variations of the original Sharpe ratio framework. For example, from the work of Young (1991) and Kestner (1996) the Sterling-Calmar ratio (see Equation 23) was developed. This ratio adopts the average of the maximum drawdowns as a risk denominator and serves as an extension of the fixed term $d$ proposed earlier. Additionally, the work of Sharpe (1966) and Keating and Shadwick (2002) inspired the development of the Omega-Sharpe ratio (see Equation 24), which builds on Markowitz's (1959) approach of adopting a semi-variance methodology. By utilising the downside potential as a substitute for the standard deviation, the Omega-Sharpe ratio introduces the sum of the returns below a desired target as an alternative denominator for the Sharpe ratio framework (adapted from Bacon 2008).

Sterling - Calmar ratio $=\frac{r_{p}-r_{f}}{\bar{D}_{\max }}$

Omega - Sharpe ratio $=\frac{r_{p}-r_{f}}{\text { Downside potential }}$

In Equation 23 and Equation 24, $r_{p}$ denotes the annualised return of the share, $r_{f}$ denotes the annualised risk-free rate, $\bar{D}_{\max }$ denotes the average of the maximum drawdowns and Downside potential $=\sum_{i=1}^{i=n} \max \left(r_{T}-r_{p}, 0\right)$, with $r_{T}$ as the minimum target. According to Bacon (2008), the OmegaSharpe ratio is simply $\Omega-1$, which should generate identical performance rankings to the original Omega $(\Omega)$ ratio that can be illustrated as follows (Keating \& Shadwick 2002):

$\Omega=\frac{\text { Upside potential }}{\text { Downside potential }}$

[Eqn 25]

In Equation 25, Upside potential $=\sum_{i=1}^{i=n} \max \left(r_{p}-r_{T}, 0\right)$ and Downside potential $=\sum_{i=1}^{i=n} \max \left(r_{T}-r_{p}, 0\right)$, with $r_{p}$ as the annualised return of the share and $r_{T}$ as the minimum target (this study will set $r_{T}=0$ ). The $\Omega$ ratio is considered superior to most traditional performance measures, as it includes all the information encoded in all the order moments (De Wet et al. 2008), which accentuates the pertinence of the OmegaSharpe framework.

In addition to the above mentioned risk denominators, the literature also presents a vast selection of alternative risk denominators and adjustments, applicable for the Sharpe ratio framework. However, this study will only add the work of Treynor and Black (1973), Grinold (1989), Modigliani and Modigliani (1997), Israelsen (2005), Pezier and White (2006), and Gatfaoui (2012) to limit the scope of this study. The three former studies introduce additional variation of the Sharpe ratio, whereas the latter three propose useful adjustments of 
the Sharpe ratio that are worth reporting. Firstly, Treynor and Black introduce a novel performance ratio (the Appraisal ratio) that adopts non-market volatility (unsystematic risk) as an admissible risk denominator to measure the fund manager's 'share-picking' and fund management skills. By converting the original Appraisal ratio to a Sharpe ratio framework, the portfolio's alpha is substituted by the excess returns as the numerator. Modifying the Appraisal ratio enables the performance measurement process to evaluate to what extent the minimum required rate of return is outperformed relative to each unit of unique risk (company-specific) that is associated with each individual share under consideration (adapted from Agarwal 2013):

Modified Appraisal ratio $=\frac{r_{p}-r_{f}}{\sqrt[2]{\sigma_{p}^{2}}-\beta_{p}^{2} \sigma_{m}^{2}}$

In Equation 26, $r_{p}$ denotes the annualised return of the share, $r_{f}$ denotes the annualised risk-free rate, $\sigma_{p}^{2}$ denotes the annualised variance of the share, $\beta_{p}$ denotes the beta of the share and $\sigma_{m}^{2}$ denotes the annualised variance of the market. An alternative performance measure is introduced by Grinold (1989), where the attributes of the Information ratio are justified from an active portfolio management perspective (see also Sharpe 1994). This ratio adopts the tracking error (active risk) as the risk denominator, which elaborates on the divergence between the share price's behaviour and the behaviour of the mark index (in this study the JSE All Share index will be used as the market proxy). By converting the Information ratio to a Sharpe ratio framework, the market excess returns are substituted with the risk-free rate excess returns as follows (adapted from Israelsen 2005):

Modified Information ratio $=\frac{r_{p}-r_{f}}{\sqrt[2]{\sigma_{p m}^{2}}}$

In Equation 27, $r_{p}$ denotes the annualised return of the share, $r_{f}$ denotes the annualised risk-free rate and $\sigma_{p m}^{2}$ denotes the annualised variance of the market excess returns $\left(r_{p}-r_{m}\right)$, with $r_{m}$ as the annualised returns of the market proxy (benchmark). Lastly, the study of Modigliani and Modigliani (1997) argues that the risk of both the share or portfolio and its benchmark must be identical in order to perform a riskadjusted performance comparison. This led to the development of the $M^{2}$ measure, which allows the portfolio manager to situate the portfolio's performance in relation to that of the market proxy (benchmark):

$M^{2}=\frac{\sigma_{m}}{\sigma_{p}}\left(r_{p}-r_{f}\right)+r_{f}$

In Equation 28, $\sigma_{m}$ denotes the annualised standard deviation of the market, $\sigma_{p}$ denotes the annualised standard deviation of the share, $r_{p}$ denotes the annualised return of the share and $r_{f}$ denotes the annualised risk-free rate. The $M^{2}$ measure holds its meaning with the presence of negative returns and is expressed in percentage points, making its interpretation sometimes easier than the traditional Sharpe ratio (Modigliani \& Modigliani 1997).
Besides the array of variations of the Sharpe ratio that are at portfolio managers' disposal, several other studies have proposed adjustments to the traditional Sharpe ratio in order to overcome two main shortfalls, entailing the inability to account for negative returns and higher moments. For example, the study of Israelsen (2005) suggests adding an exponent to the standard deviation (risk denominator), in order to improve the Sharpe ratio estimate when excess returns $\left(r_{p}-r_{f}\right)$ are negative (Israelsen 2005):

Israelsen's modified Sharpe ratio $=\frac{r_{p}-r_{f}}{\sigma_{p}^{\left(\frac{E R}{a b s . E R}\right)}}$

In Equation 29, $r_{p}$ denotes the annualised return of the share, $r_{f}$ denotes the annualised risk-free rate, $\sigma_{p}$ denotes the annualised standard deviation of the share and $E R=\left(r_{p}-r_{f}\right)$, where abs.ER denotes the absolute value of $E R$. In terms of adjusting for higher moments, the studies of Pezier and White (2006) and Gatfaoui (2012) proposed two different techniques. Pezier and White suggest the explicit adjustment for skewness and kurtosis, by incorporating a penalty factor for negative skewness and excess kurtosis as follows:

Pezier and White's $\left(P W^{\prime}\right.$ 's ) adjusted Sharpe ratio

$$
=S R \times\left[1+\left(\frac{S}{6}\right) \times S R-\left(\frac{K-3}{24}\right) \times S R^{2}\right]
$$

In Equation 30, $S R$ denotes the traditional Sharpe ratio estimate, $S$ denotes skewness and $K$ denotes kurtosis. On the other hand, Gatfaoui (2012) proposes scaling the traditional Sharpe and Treynor ratios to account for both skewness and kurtosis as follows:

Scaled Sharpe ratio $1\left(S^{*}\right)=w_{-} \times \frac{e x_{-}}{\sigma_{p_{-}}}+w_{+} \times \frac{e x_{+}}{\sigma_{p_{+}}}$

Scaled Sharpe ratio $2\left(S^{* *}\right)=w_{-} \times \frac{r_{p}-r_{f}}{\sigma_{p_{-}}}+w_{+} \times \frac{r_{p}-r_{f}}{\sigma_{p_{+}}}$[Eqn 32]

Scaled Treynor ratio $1\left(T^{*}\right)=\frac{r_{p}-r_{f}}{\beta^{*}}$

[Eqn 33]

Scaled Treynor ratio $2\left(T^{* *}\right)=w_{M-} \times \frac{r_{p}-r_{f}}{\beta_{-}}+w_{M+} \times \frac{r_{p}-r_{f}}{\beta_{+}}$

[Eqn 34]

In Equations 31-34, $w_{-}=n_{-} \div n$ and $w_{+}=n_{+} \div n$, with $n_{-}$and $n_{+}$denoting the number of observations below and above the mean of the share's returns and $n$ denoting the total number of observations under investigation. Additionally, $w_{M-}=m_{-} \div m$ and $w_{M+}=m_{+} \div m$, with $m_{-}$and $m_{+}$denoting the number of observations below and above the mean of the market's returns and $m$ denoting the total number of observations under investigation. $e x_{-}$denotes negative excess returns $\left(r_{p}-r_{f}\right), e x_{+}$denotes positive excess returns $\left(r_{p}-r_{f}\right), \sigma_{p}$ denotes the annualised standard deviation of the share, where $\sigma_{p-}$ and $\sigma_{p+}$ denote the downside and upside deviations of the security, $\sigma_{p m}$ denotes the covariance between 
the security and the market under evaluation, $\sigma_{M-}^{2}$ and $\sigma_{M+}^{2}$ denote the downside and upside deviations of the market, $r_{p}$ denotes the annualised return of the security and $r_{f}$ denotes the annualised risk-free rate. In Equation 33, $\beta^{*}=w_{M-} \frac{\sigma_{p M}}{\sigma_{M-}^{2}}+w_{M+} \frac{\sigma_{p M}}{\sigma_{M+}^{2}}$ and in Equation 34 $\beta_{-}=\frac{\sigma_{p M}}{\sigma_{M-}^{2}}$ and $\beta_{+}=\frac{\sigma_{p M}}{\sigma_{M+}^{2}}$. Gatfaoui (2012) argues that rendering the Sharpe and Treynor ratios more homogeneous in terms of skew risk and offsetting the related skew-based biases will improve portfolio decision-making.

\section{Method and data}

The scope of this study will be limited to the risk-adjusted performance ratios with the attributes derived from the different adjustments or suggested amendable risk measures as summarised in Table 1. Each of these ratios will provide a unique perspective and was selected to address the most common obstacles observed in portfolio selection and performance evaluation (see Table 1 and previous section). Each of these ratios was used to compile its own representative long-only equity portfolio, which consisted of 40 shares that were selected from an investment universe of 583 listed and 357 delisted South African shares. The performance of each portfolio was then compared and evaluated against equity market, money market and bond market proxies (each representing a buy-and-hold strategy), from a one-year, three-year and five-year momentum investment strategy. Every one, three and five years each portfolio will be rebalanced based solely on the new set of rankings provided by each of the 24 Sharpe ratio variations under evaluation.
Since the literature has already provided evidence that portfolio and individual share returns exhibit non-normal distributions, overall risk-adjusted outperformance will be measures based on an index that is compiled from seven categories. Each of these categories will provide a different risk-adjusted perspective that will help to derive a comprehensive conclusion, which is not restricted to the assumption of normal returns and will incorporate both an upside and downside risk and performance perspective. These categories entail geometric returns, upside potential (returns above zero and scaled according to the number of observations), downside potential (returns below zero and scaled according to the number of observations), standard deviation, maximum downturn (maximum loss from peak to succeeding trough), upside risk (returns above zero) and downside risk (returns below zero).

This study will consult two sets of index rankings to derive a final conclusion. The first set of rankings (equally weighted) will assign the same weight to all seven categories, whereas the second set of rankings (50:50 weighting) will assign 25\% to geometric returns and upside potential, and will divide the remaining $50 \%$ evenly between the risk measures, namely downside potential, standard deviation, maximum downturn, upside risk and downside risk. To validate this index approach, Table 2 and Table 3 report on the level of normality of the individual share returns (of the data distributions) and the preliminary portfolio return statistics to be consulted.

Table 2 emphasises the results of Van Heerden (2015), who confirmed the presence of higher moments and non-normal

TABLE 1: Summary of risk-adjusted performance methodology.

\begin{tabular}{|c|c|c|}
\hline Ratio & Source & Risk denominator utilised or adjustment made to the Sharpe ratio framework \\
\hline Traditional Treynor & Treynor (1965) & Beta (systematic or market risk) \\
\hline Traditional Sharpe & Sharpe (1966) & Standard deviation (total risk) \\
\hline Sortino & Sortino and Van der Meer (1991) & Downside risk (LPMs of the second order) \\
\hline Calmar & Young (1991) & Maximum drawdown (LPM application) \\
\hline Burke & Burke (1994) & \multirow{2}{*}{$\begin{array}{l}\text { Maximum drawdown variation } \\
\text { (LPM application) }\end{array}$} \\
\hline Sterling & Adjusted from Kestner (1996) & \\
\hline$M^{2}$ & Modigliani and Modigliani (1997) & Market-related perspective, using a standard deviation comparison \\
\hline Martin & Martin and McCann (1998) & Maximum drawdown variation (LPM application) \\
\hline VaR-Sharpe & Dowd $(1999,2000)$ & $\begin{array}{l}\text { Value-at-risk, to account for the probability of loss, at a certain confidence level over } \\
\text { a certain time horizon }\end{array}$ \\
\hline Serial correlation-adjusted Sharpe & Lo (2002) & Adjust for serial correlation \\
\hline Modified VaR-Sharpe & Gregoriou and Gueyie (2003) & Value-at-risk variation to account for more outliers \\
\hline Kappa 3 & Kaplan and Knowles (2004) & LPMs of the third order \\
\hline Modified Information & Adapted from Israelsen (2005) & Tracking error \\
\hline Israelsen's modified Sharpe & Israelsen (2005) & Standard deviation variation to account for higher moments and negative returns \\
\hline Pain & Zephyr Association (2006) & A maximum drawdown variation (LPM application) \\
\hline Pezier \& White's adjusted Sharpe & Pezier and White (2006) & Adjustment for skewness and kurtosis \\
\hline Sterling-Calmar & Adapted from Bacon (2008) & A maximum drawdown variation (LPM application) \\
\hline Omega-Sharpe & Adapted from Bacon (2008) & Downside potential (LPM application) \\
\hline Conditional VaR-Sharpe & Esfahanipour and Mousavi (2011) & Value-at-risk variation, to account for expected shortfall \\
\hline Scaled Sharpe 1 (S*) & Gatfaoui (2012) & Adjustment for skewness and kurtosis \\
\hline Scaled Sharpe 2 (S**) & Gatfaoui (2012) & Adjustment for skewness and kurtosis \\
\hline Scaled Treynor ratio $1\left(T^{*}\right)$ & Gatfaoui (2012) & Adjustment for skewness and kurtosis \\
\hline Scaled Treynor ratio $2\left(\mathrm{~T}^{* *}\right)$ & Gatfaoui (2012) & Adjustment for skewness and kurtosis \\
\hline Modified Appraisal ratio & Adapted from Agarwal (2013) & Unique risk (company-specific or unsystematic risk) \\
\hline
\end{tabular}

LPM, lower partial moment; VaR, value-at-risk. 
distributions in the South African equities market. Share returns exhibited platykurtic, leptokurtic, and normal and non-normal distribution characteristics, making a comparative performance evaluation with only traditional risk-adjusted performance ratios, such as the traditional Sharpe and Treynor ratios, impossible (see Table 2). Based on the study of Harlow (1991) and Lhabitant (2004), these results imply that risk measures that are derived from or are variation of variance (e.g. standard deviation and beta) will

TABLE 2: Descriptive statistics of shares.

\begin{tabular}{|c|c|c|c|c|c|}
\hline Year & $\begin{array}{l}\text { Number of } \\
\text { shares not } \\
\text { normally } \\
\text { distributed }\end{array}$ & $\begin{array}{l}\text { Number of } \\
\text { shares } \\
\text { platykurtic }\end{array}$ & $\begin{array}{l}\text { Number of } \\
\text { shares } \\
\text { leptokurtic }\end{array}$ & $\begin{array}{l}\text { Number of } \\
\text { shares } \\
\text { positively } \\
\text { skewed }\end{array}$ & $\begin{array}{c}\text { Number of } \\
\text { shares } \\
\text { negatively } \\
\text { skewed }\end{array}$ \\
\hline 2000 & 150 & 536 & 70 & 290 & 316 \\
\hline 2001 & 139 & 454 & 70 & 255 & 269 \\
\hline 2002 & 121 & 389 & 53 & 212 & 231 \\
\hline 2003 & 109 & 331 & 61 & 223 & 169 \\
\hline 2004 & 96 & 312 & 45 & 187 & 170 \\
\hline 2005 & 86 & 302 & 35 & 170 & 167 \\
\hline 2006 & 87 & 289 & 52 & 164 & 177 \\
\hline 2007 & 114 & 328 & 53 & 204 & 177 \\
\hline 2008 & 71 & 351 & 32 & 191 & 192 \\
\hline 2009 & 77 & 345 & 33 & 176 & 202 \\
\hline 2010 & 54 & 346 & 24 & 172 & 198 \\
\hline 2011 & 54 & 339 & 26 & 189 & 177 \\
\hline 2012 & 61 & 331 & 28 & 188 & 171 \\
\hline 2013 & 68 & 318 & 31 & 192 & 157 \\
\hline 2014 & 71 & 312 & 34 & 184 & 162 \\
\hline 2015 & 76 & 311 & 30 & 180 & 161 \\
\hline 2016 & 64 & 306 & 28 & 175 & 159 \\
\hline 2017 & 64 & 304 & 32 & 187 & 149 \\
\hline
\end{tabular}

Note: The Shapiro-Wilk, Anderson-Darling, Lilliefors and Jarque-Bera normality tests were used. If the majority reported the rejection of the null hypothesis, then it was reported as not normally distributed. If a share generated no returns (e.g. delisted) during the time period, if was excluded from the estimation process. exhibit the tendency to underestimate the level of actual risk. This justifies the notion that a risk-adjusted performance evaluation process must distinguish between upside and downside risk or performance. This firstly substantiates the use of the seven different categories (and not only standard deviation as a risk measure) to derive more comprehensive risk-adjusted performance evaluation scores; secondly, it implies that traditional risk-adjusted performance ratios should not be consulted in isolation, and that other ratios (as reported in Table 1) that make use of alternate risk denominators that distinguish between upside and downside risk must also be consulted to construct the long-only equity portfolios.

Additionally, in order to justify the number of shares that must be included in a portfolio, the literature was consulted. However, there is no consensus regarding what is the optimal number of shares in an equity portfolio that will be beneficial from a diversification or risk-adverse point of view. Although the optimal number of shares would ultimately depend upon the investor's life cycle, strategy, goals, risk preference and other constraints, the universe of shares being analysed and the weighting scheme used to construct portfolios, studies such as Evans and Archer (1968), Statman (1987) and Tang (2004) argue that between 10 and 40 shares will be adequate. According to Newbould and Poon (1993), 20 shares can lead to a risk-efficient portfolio; however, Domian et al. (2007) argue that portfolios of $8-20$ shares will be inadequate, as long-term investors will not be able to outperform treasury bonds. Nevertheless, the results from Table 3 justify the notion of including only 40 shares in an equity portfolio, as the portfolios that were constructed in this study were able to

TABLE 3: Portfolio composition statistics.

\begin{tabular}{|c|c|c|c|c|c|}
\hline Variables & Types & Description categories & $\%$ & Description categories & $\%$ \\
\hline \multirow{9}{*}{$\begin{array}{l}\text { Constructed } \\
\text { portfolios }\end{array}$} & \multirow{3}{*}{$\begin{array}{l}\text { Portfolios with a one-year } \\
\text { momentum investment strategy }\end{array}$} & Maximum annual risk-adjusted returns & 39.22 & Minimum annual variance & 0.00 \\
\hline & & Average annual risk-adjusted returns & 10.01 & Maximum annual variance & 0.02 \\
\hline & & Average annual standard deviation & 0.68 & Maximum annual standard deviation & 1.46 \\
\hline & \multirow{3}{*}{$\begin{array}{l}\text { Portfolios with a three-year } \\
\text { momentum investment strategy }\end{array}$} & Maximum annual risk-adjusted returns & 40.63 & Minimum annual variance & 0.00 \\
\hline & & Average annual risk-adjusted returns & 5.20 & Maximum annual variance & 0.03 \\
\hline & & Average annual standard deviation & 0.61 & Maximum annual standard deviation & 1.68 \\
\hline & \multirow{3}{*}{$\begin{array}{l}\text { Portfolios with a five-year } \\
\text { momentum investment strategy }\end{array}$} & Maximum annual risk-adjusted returns & 34.01 & Minimum annual variance & 0.00 \\
\hline & & Average annual risk-adjusted returns & 2.49 & Maximum annual variance & 0.02 \\
\hline & & Average annual standard deviation & 0.52 & Maximum annual standard deviation & 1.33 \\
\hline \multirow{14}{*}{$\begin{array}{l}\text { Buy-and-hold } \\
\text { strategy proxies }\end{array}$} & \multirow{3}{*}{$\begin{array}{l}\text { JSE Top } 40 \text { index (equity market) } \\
\text { from } 2001 \text { to } 2017\end{array}$} & Maximum annual risk-adjusted returns & 31.94 & Minimum annual variance & 0.40 \\
\hline & & Average annual risk-adjusted returns & 10.81 & Maximum annual variance & 7.77 \\
\hline & & Average annual standard deviation & 12.98 & Maximum annual standard deviation & 27.88 \\
\hline & \multirow{2}{*}{$\begin{array}{l}\text { JSE All Share index (equity market) } \\
\text { from } 2001 \text { to } 2017\end{array}$} & Maximum annual risk-adjusted returns & 32.02 & Minimum annual variance & 0.31 \\
\hline & & Average annual risk-adjusted returns & 10.50 & Maximum annual variance & 6.75 \\
\hline & \multirow{3}{*}{$\begin{array}{l}\text { 12-month JIBAR (money market proxy) } \\
\text { from } 2005 \text { to } 2017\end{array}$} & Maximum annual risk-adjusted returns & 25.13 & Minimum annual variance & 0.19 \\
\hline & & Average annual risk-adjusted returns & 1.52 & Maximum annual variance & 3.43 \\
\hline & & Average annual standard deviation & 9.89 & Maximum annual standard deviation & 18.52 \\
\hline & \multirow{3}{*}{$\begin{array}{l}\text { 1-3-year bond index (bond market) } \\
\text { from } 2005 \text { to } 2017\end{array}$} & Maximum annual risk-adjusted returns & 4.89 & Minimum annual variance & 0.01 \\
\hline & & Average annual risk-adjusted returns & -12.97 & Maximum annual variance & 0.17 \\
\hline & & Average annual standard deviation & 1.88 & Maximum annual standard deviation & 4.15 \\
\hline & \multirow{3}{*}{$\begin{array}{l}\text { 3-7-year bond index (bond market) } \\
\text { from } 2005 \text { to } 2017\end{array}$} & Maximum annual risk-adjusted returns & 16.45 & Minimum annual variance & 0.05 \\
\hline & & Average annual risk-adjusted returns & -1.22 & Maximum annual variance & 0.78 \\
\hline & & Average annual standard deviation & 4.18 & Maximum annual standard deviation & 8.85 \\
\hline
\end{tabular}

JSE, Johannesburg Stock Exchange.

Note: The risk-adjusted returns were estimated by dividing the average returns by the standard deviation. 
generate a low volatility (standard deviation), ranging between $0 \%$ and $1.68 \%$ over the different portfolios and investment horizons under evaluation.

The results from Table 3 also substantiate the appeal of a 40-share portfolio, as it exhibited not only the ability to produce the lowest volatility, but also the highest annual risk-adjusted returns compared to all the buy-and-hold proxies, from a one-year, three-year and five-year momentum investment strategy perspective. This accentuates that a 40-share portfolio can be beneficial for both active and more passive equity portfolio managers. Even though Table 3 reports lower average annual riskadjusted returns across all the portfolios under evaluation, compared to all the buy-and-hold proxies, from a one-year, three-year and five-year momentum investment strategy perspective, it only highlights the importance of identifying the risk-adjusted ratios with the ability to promote continuity in terms of identifying a portfolio composition that will always outperform the market from a risk-adjusted perspective. Not all risk-adjusted ratios can lead to profitable portfolio compositions, which can be explained by the lower average annual risk-adjusted returns across all the different portfolios under evaluation compared to the buy-and-hold market proxies.

Regarding the data, this study uses monthly share price data, spanning from January 2000 to December 2017, that were sourced from IRESS (2019), where the natural logs were used to estimate the share returns, which were also adjusted for dividends and splits. The JSE All Share (J203) index was used as the overall market proxy (benchmark) in the estimation of applicable ratios, whereas the J203 and the JSE Top 40 (J200) index were used as proxies for equity buy-and-hold strategies. The 12-month JIBAR rate, and the 1-3-year and 3-7-year bond indices were used as proxies to present money market and bond market buy-and-hold strategies, which were all sourced from IRESS (2019). The returns of the money market and bond market proxies were converted to monthly yieldto-maturities before commencing with the risk-adjusted performance evaluation process. Due to data unavailability the money market and bond index proxies could only be consulted from 2005. Furthermore, based on the findings and arguments posed by Van Heerden (2016) and Grandes and Pinaud (2004), this study utilises the three-month Negotiable Certificates of Deposits (NCDs) rate as the risk-free rate proxy, which was sourced from the South African Reserve Bank (SARB) (2019). However, due to the unavailability of data the transaction costs and taxes involved in the portfolio rebalancing process were excluded from this study.

\section{Ethical consideration}

Ethical clearance was not required for the study.

\section{Results}

From the results reported by Tables 4-6 (the 50:50 weighting approach), it is evident that there is no consistency in terms of the best-performing ratio between the three momentum investment strategies or over the different time periods under evaluation. These results accentuate the study of Van Heerden and Coetzee (2019), who also recognised the difficulty of establishing an 'all-inclusive' group of ratios that will ensure continuous profitable share selections. However, by dividing the 24 Sharpe ratio variations into four quantiles, ranked from best to worst, a more comprehensive performance comparison could be derived. Even with the first quantile of performing ratios exhibiting a varying composition over time, the portfolio compositions derived from the first quantile of performing ratios were able to outperform all the buy-and-hold proxies under evaluation (see Tables 4-6). The only two exceptions were in 2006 (for the five-year momentum investment strategy) and 2007 (for all the momentum investment strategies), where not all ratios in the first quantile were able to outperform the equity market and the money market buy-and-hold proxies. Even with the shortcomings of beta as a risk denominator (as acknowledged above), it was interesting to note that the traditional Treynor ratio yielded the best-performing portfolio during the 2008-financial crisis period, from a one-year momentum investment strategy perspective. However, from a five-year momentum investment strategy perspective the Appraisal ratio yielded a better-performing portfolio. The relevance of adjusting for kurtosis and skewness, as proposed by Gatfaoui (2012), is also highlighted by the dominance of the scaled Sharpe ratio $1\left(\mathrm{~S}^{*}\right)$ during the financial crisis period from a three-year momentum investment strategy perspective. In addition, the importance of adjusting for SC, skewness and kurtosis after the financial crisis period can be accentuated by the results reported by Tables 4-6, which support the findings of Chatterjee et al. (2015). Tables 4-6 report that the SC-adjusted Sharpe, the $\mathrm{S}^{*}$, the scaled Sharpe ratio $2\left(\mathrm{~S}^{* *}\right)$, and the scaled Treynor ratio 1 and 2 ( $\mathrm{T}^{*}$ and $\mathrm{T}^{* *}$ ) exhibited a greater tendency to rank under the first quantile of performing ratios, from a one-year, three-year and five-year momentum investment strategy perspective. Furthermore, it is worth noting that the VaR-Sharpe ratio exhibited the highest consistency in ranking under the first quantile of performing ratios, from a one-year and five-year momentum investment strategy perspective, with the only exception during the prefinancial crisis period from a three-year momentum investment strategy perspective. The runner-up entailed the Appraisal ratio, which also exhibited some consistency in ranking under the first quantile of performing ratios. However, the only exception was during the post-financial crisis period from a three-year momentum investment strategy perspective (see Tables 4-6).

Even with some ratios exhibiting consistency in terms of outperformance, the implication of these results is that active and more passive portfolio managers will have to consult different compositions of ratios in order to ensure a more profitable share selection process. From Tables $4-6$ it is, however, evident that all 24 constructed portfolios were able to outperform the J200 index in 2008 and in 2016 from a one-year, three-year and five-year momentum investment 


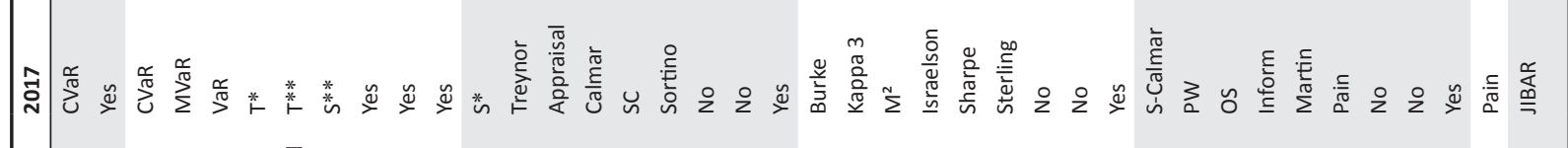

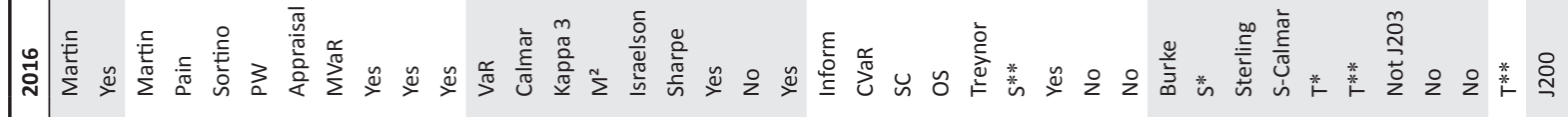

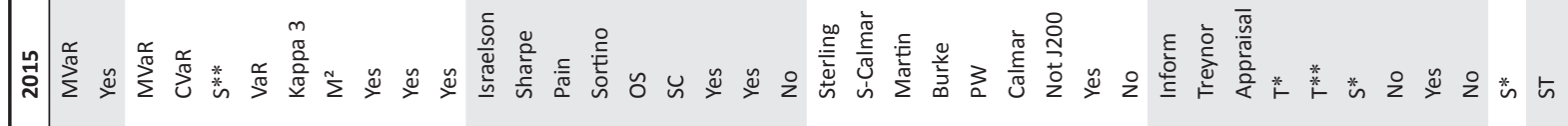

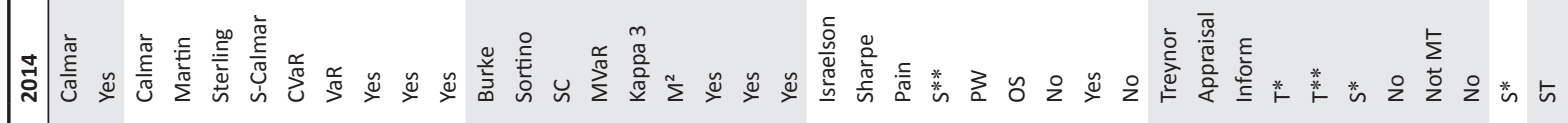

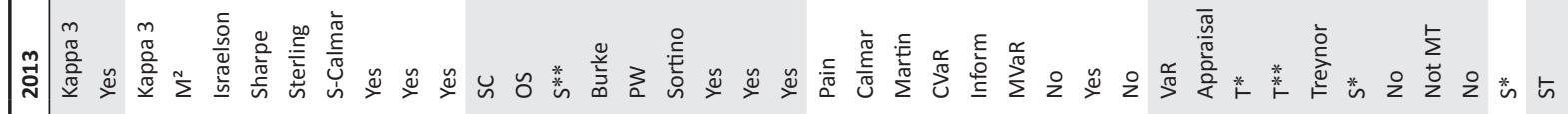

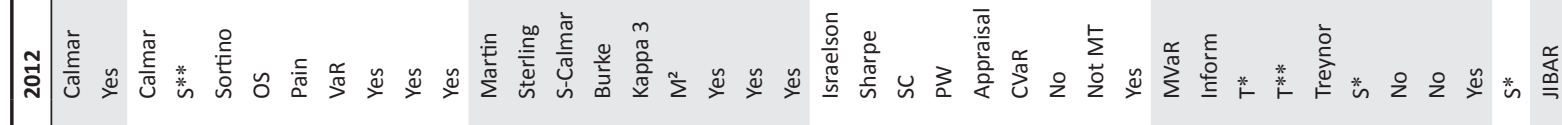

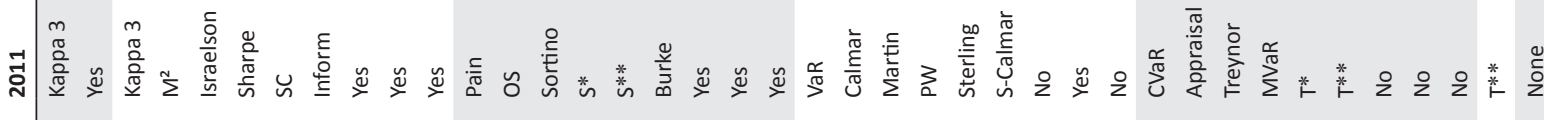

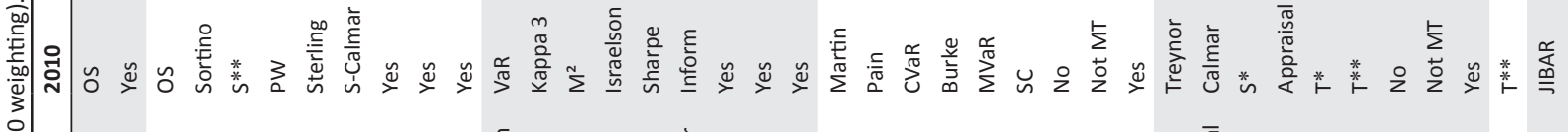

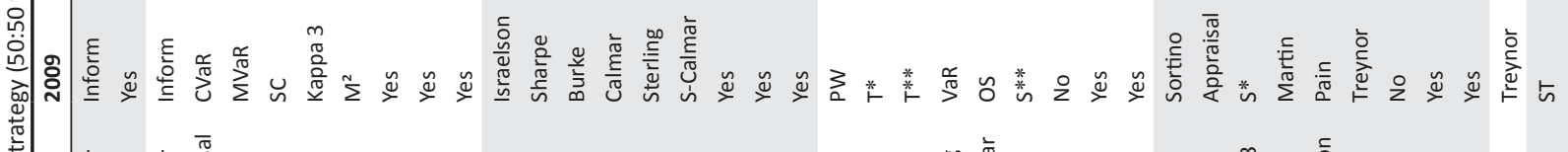

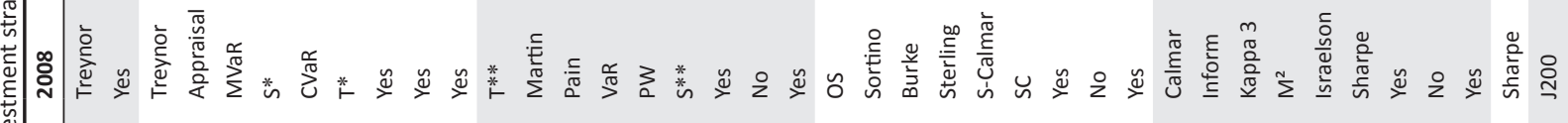

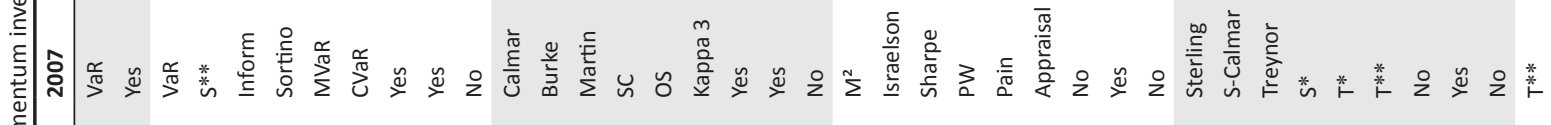

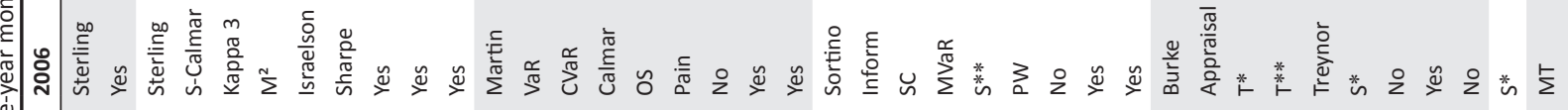

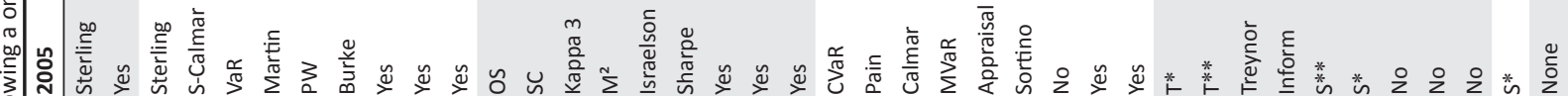

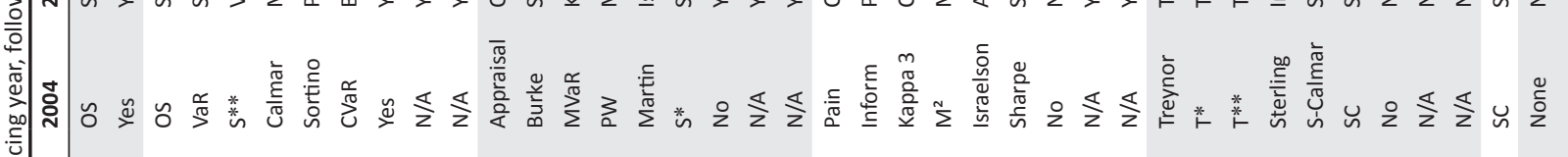

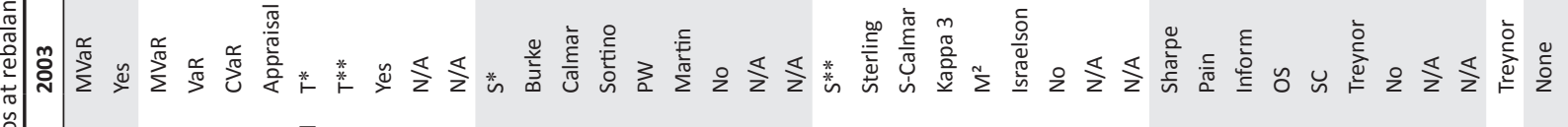

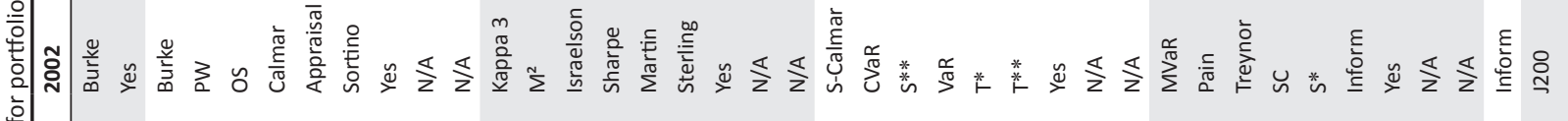

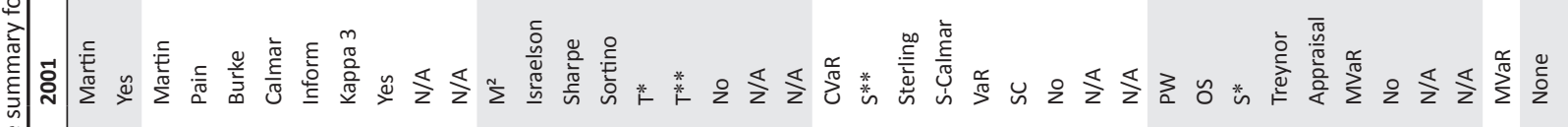

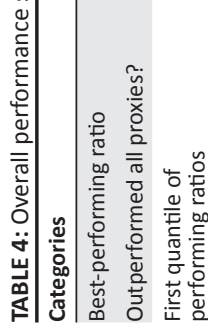
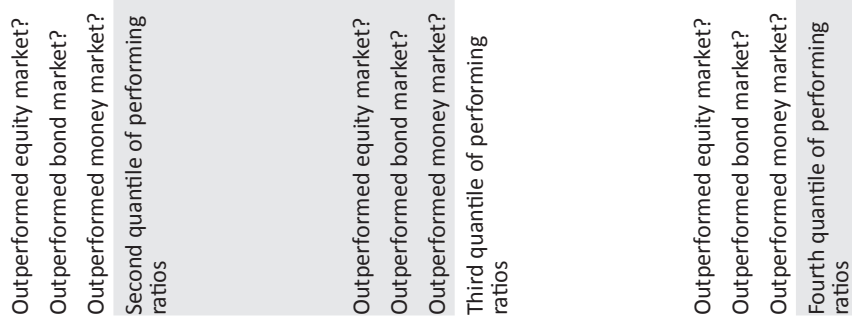

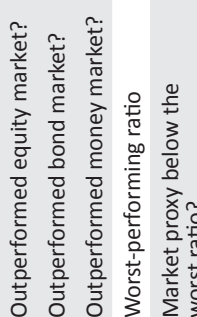




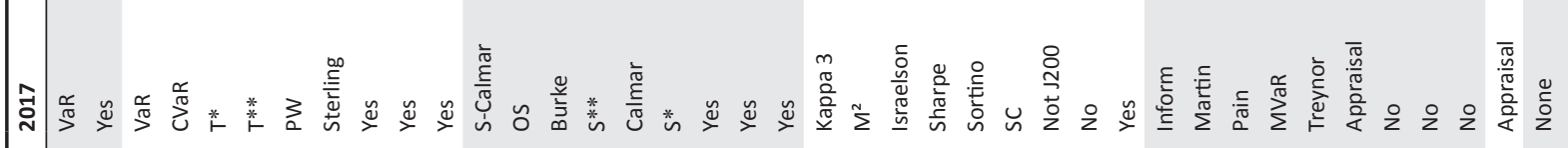

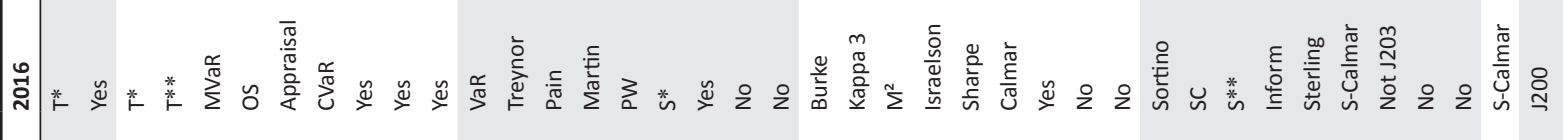

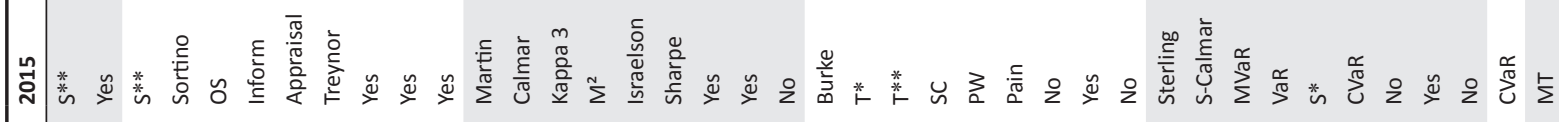

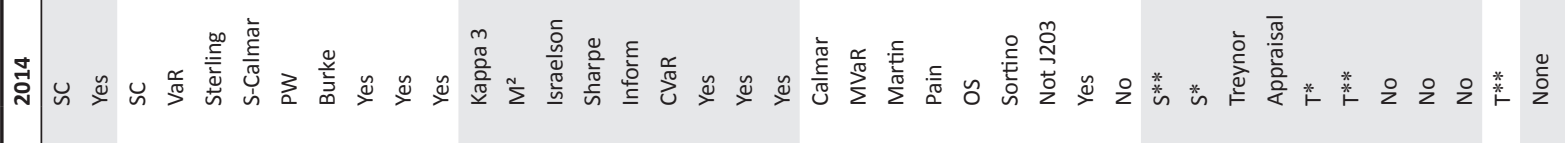

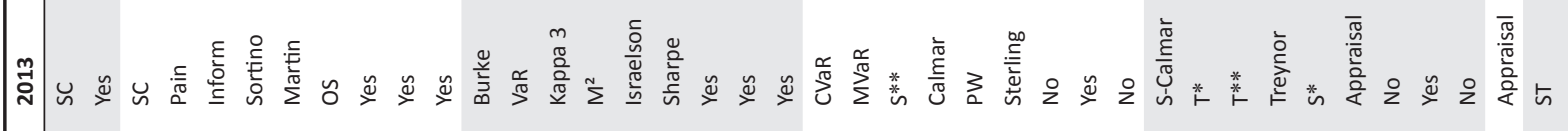

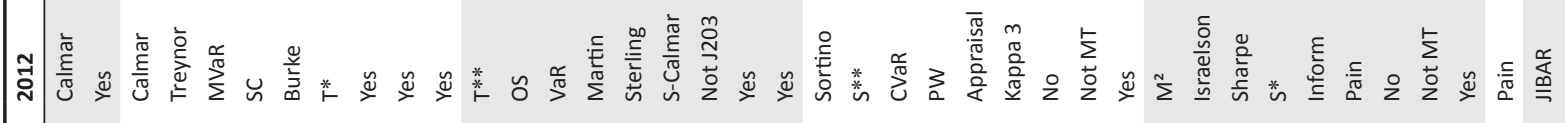

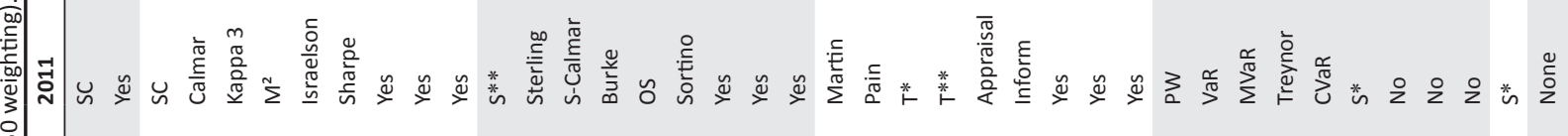

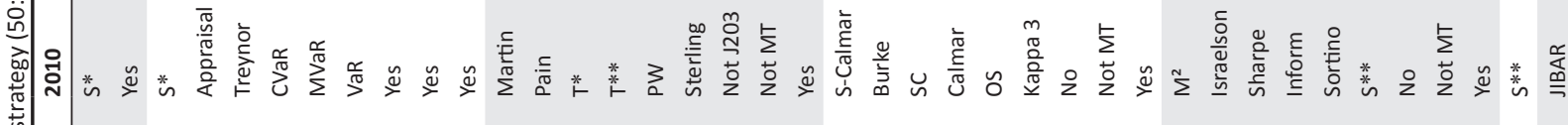

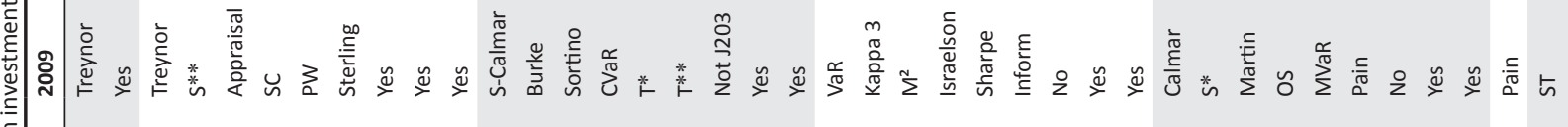

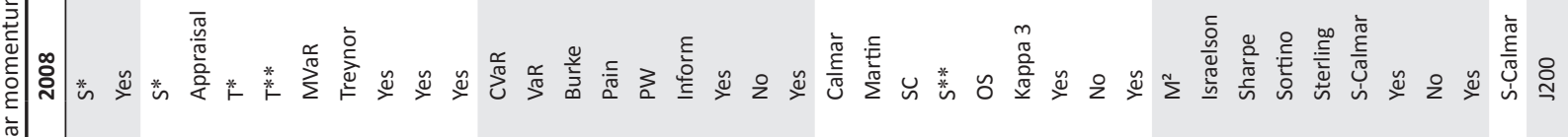

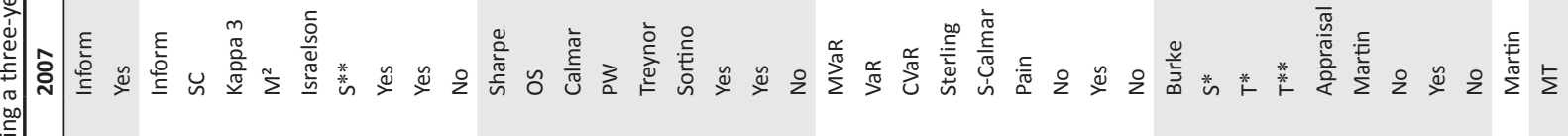

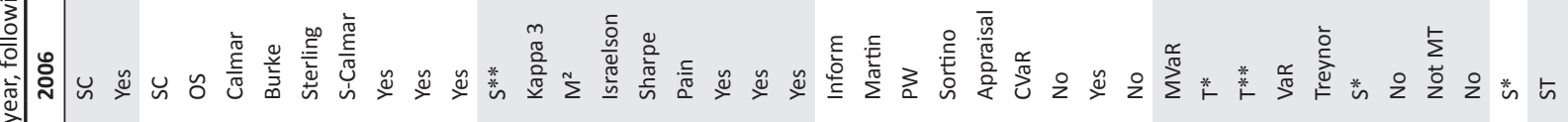

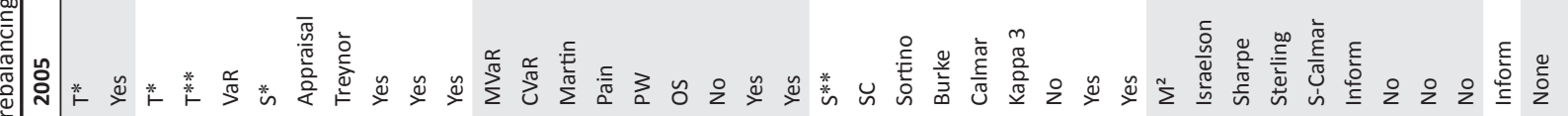

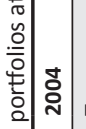

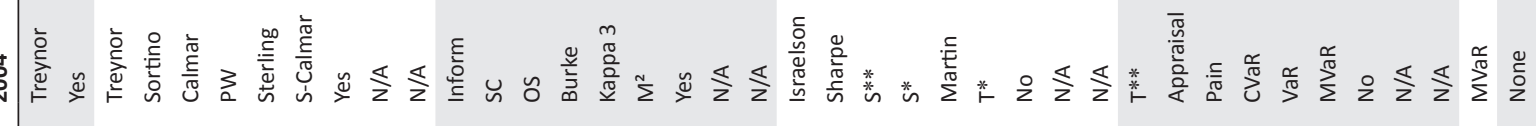

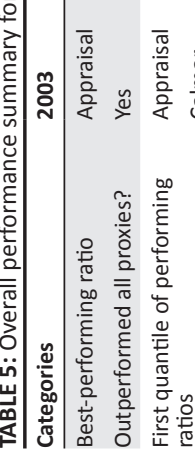

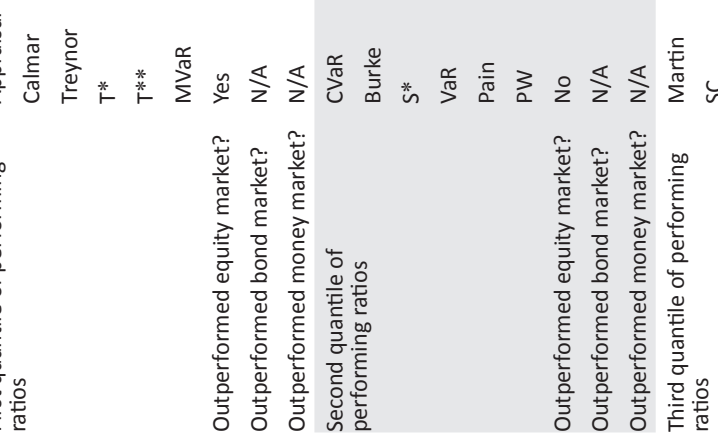

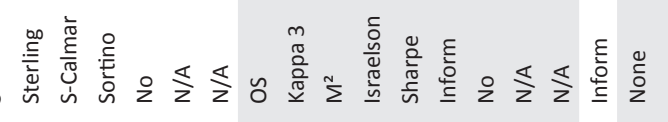

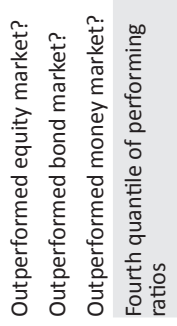

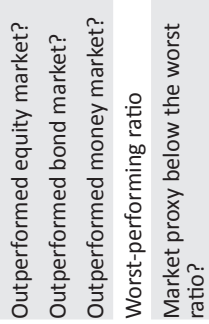




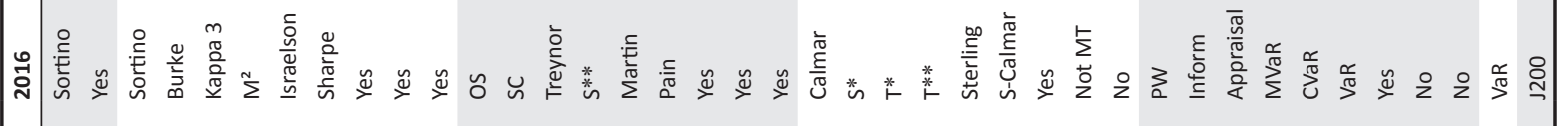

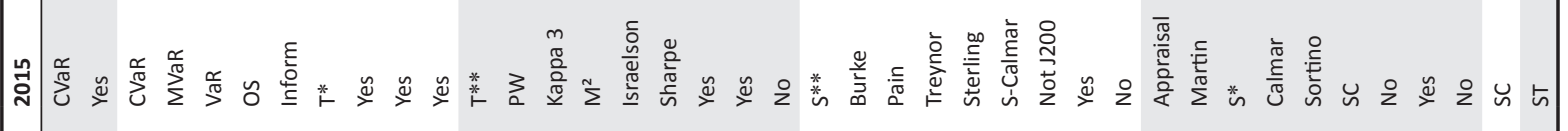

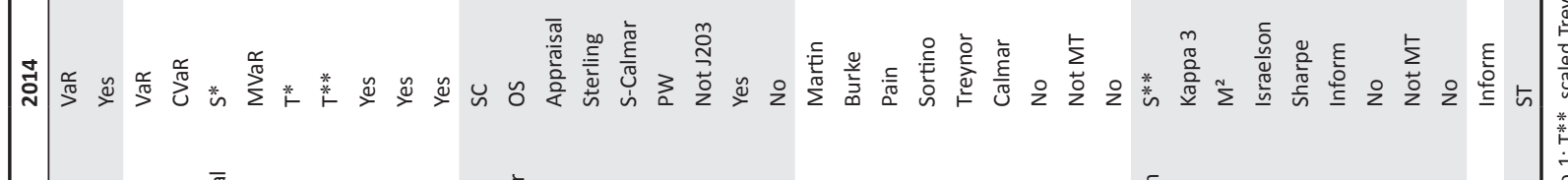

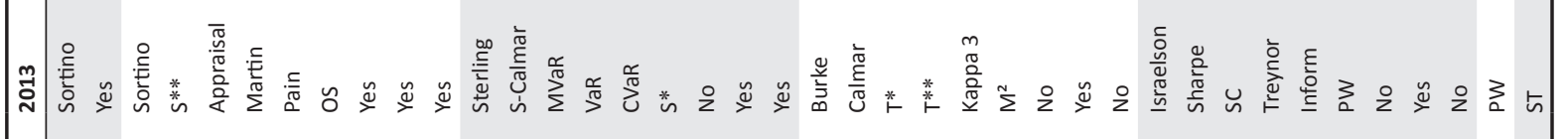

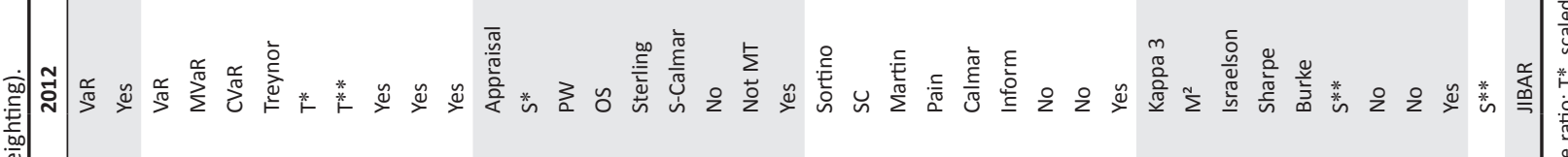

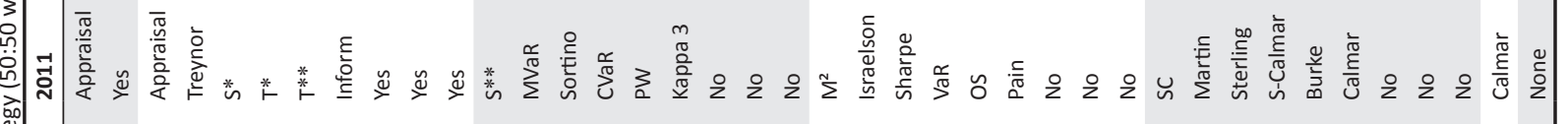

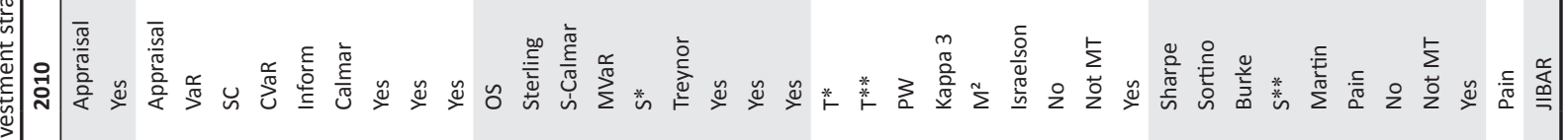

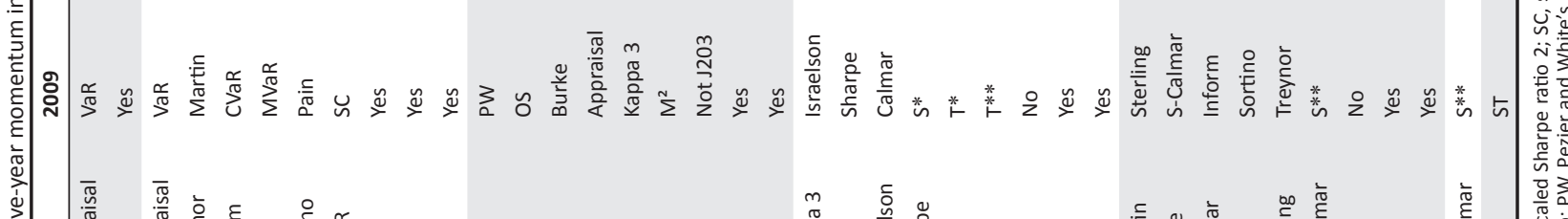

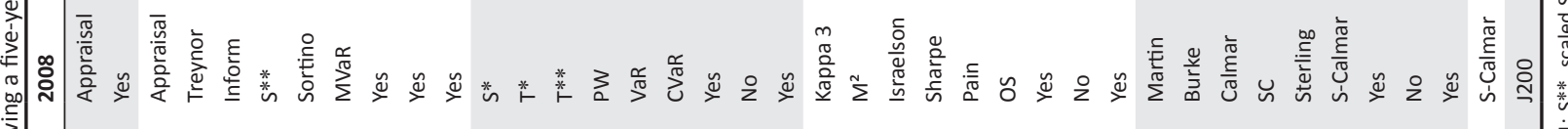

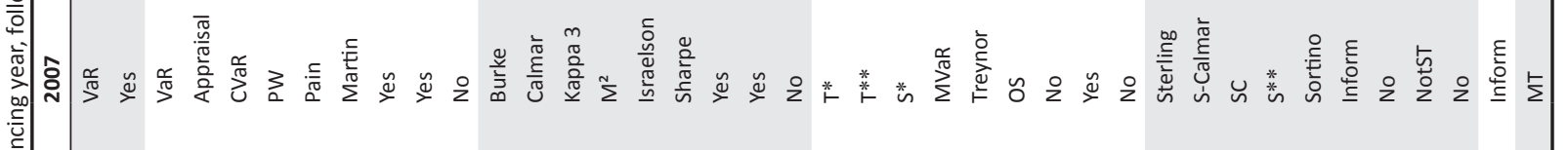

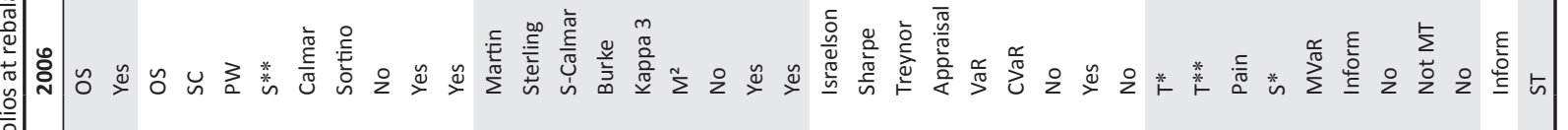
0
0 


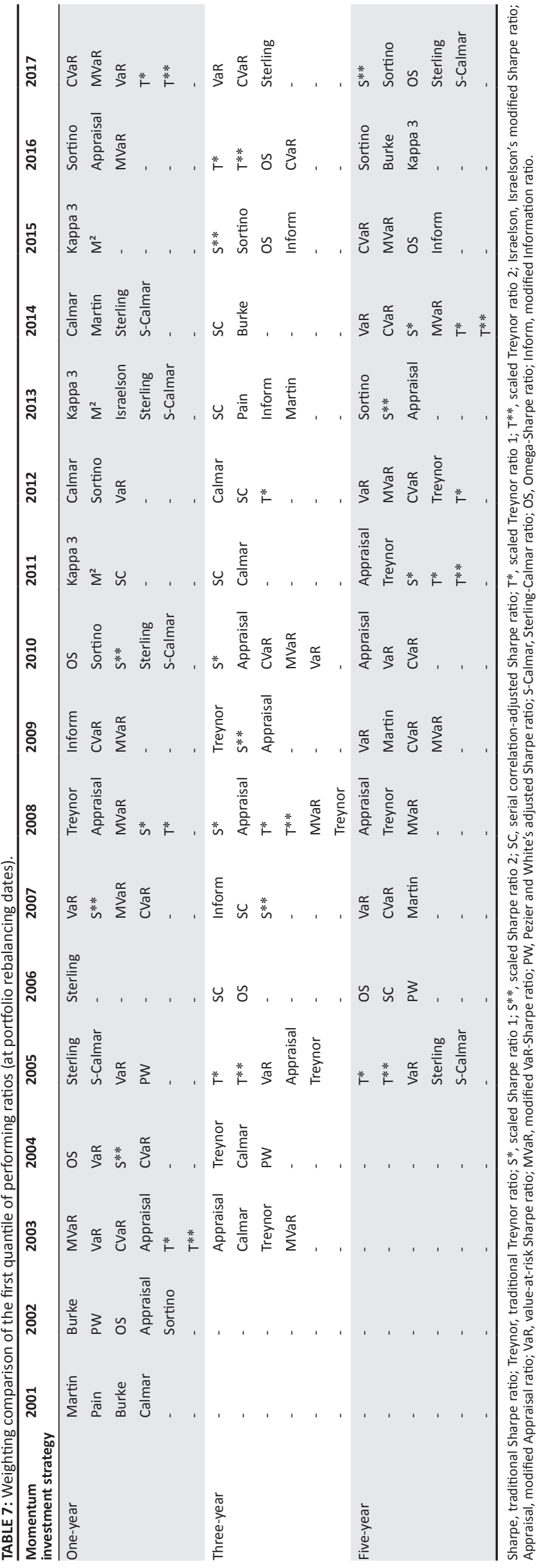

strategy perspective. Moreover, all 24 constructed portfolios were able to outperform the money market buy-and-hold proxy in 2008, 2009, 2010 and 2012 and the 1-3-year index or the 3-7-year bond index in 2006, 2007, 2009, 2010, 2013 and 2015. This implies that all markets are not always information efficient, which suggests the ability of active portfolio managers to outperform the market for only certain time durations (see also Heymans \& Santana 2018). The inconsistent presence of outperformance may further suggest the existence of time-varying market (information) efficiency, which accentuates the studies of McMillan and Thupayagale (2008) and Bonga-Bonga (2012).

Nevertheless, it is still difficult to establish ratio dominance by consulting only Tables $4-6$. Consequently, to enhance the insight of ratio dominance from a momentum investment strategy perspective, a comparison was done with both the 50:50 and equally weighted ranking approaches, as reported in Table 7 (but only for the first quantile of performing ratios). The motivation for this approach was based on the notion that the equally weighted approach yielded similar results to that of the 50:50 ranking approach in terms of outperforming the buy-and-hold proxies, although the compositions of the first quantile of performing ratios differed slightly. Also, as overall dominance only rests with the first quantile of performing ratios, the author did not deem it necessary to duplicate the reporting style of Tables 4-6 for the equally weighted approach; however, these results are available on request. The results from Table 7 accentuate the notion of Sharpe (1994), who acknowledged the ambiguity of the Sharpe ratio's predictive properties. Besides the fact that the traditional Sharpe ratio was never able to produce a more dominant portfolio composition, Table 7 reports that only variations of the traditional Sharpe ratio accomplished that feat. The results again emphasise the VaR-Sharpe ratio's consistency in ranking under the first quantile of performing ratios, as derived from Tables 4-6. Additionally, Table 7 reports that the VaR-Sharpe ratio yielded the best-performing portfolio in 2007 from a one-year and five-year momentum investment strategy perspective, in 2017 from a three-year momentum investment strategy perspective and in 2009, 2012 and 2014 from a five-year momentum investment strategy perspective. The dominance of this ratio may be explained by the presence of more non-normally distributed share returns in the VaR-Sharpe portfolios compared to other competing portfolios during the period of outperformance. Even with the shortcomings of $\mathrm{VaR}$ as a risk denominator (as stipulated earlier), it seems that this risk denominator was able to capture more of the outliers and asymmetric features of the returns compared to the other risk denominators under evaluation, thus providing a more accurate risk-adjusted performance evaluation during the share selection process. The applicability of the VaR-Sharpe can further be motivated by Figure 1, which reports the correlation between the different portfolios that were derived from the top-ranking ratios as reported by Table 7 and Table 8. During 2007, 2009, 2012 and 2014 the highest correlation with a VaR-Sharpe portfolio was $82.50 \%$ and $75 \%$ (and highest average correlation of $84.71 \%$ 
TABLE 8: Overall summary of credibility of ratios.

\begin{tabular}{|c|c|c|c|c|c|c|c|}
\hline \multicolumn{2}{|c|}{$\begin{array}{l}\text { One-year momentum } \\
\text { investment strategy }\end{array}$} & \multicolumn{2}{|c|}{$\begin{array}{l}\text { Three-year momentum } \\
\text { investment strategy }\end{array}$} & \multicolumn{2}{|c|}{$\begin{array}{l}\text { Five-year momentum } \\
\text { investment strategy }\end{array}$} & \multicolumn{2}{|c|}{ Overall } \\
\hline $\begin{array}{l}\text { Ratio } \\
\text { responsible }\end{array}$ & $\begin{array}{c}\text { Portion of events } \\
\text { which yielded the } \\
\text { best-performing } \\
\text { portfolio (\%) }\end{array}$ & Ratio responsible & $\begin{array}{l}\text { Portion of events } \\
\text { which yielded the } \\
\text { best-performing } \\
\text { portfolio }(\%)\end{array}$ & Ratio responsible & $\begin{array}{c}\text { Portion of events } \\
\text { which yielded the } \\
\text { best-performing } \\
\text { portfolio }(\%)\end{array}$ & Ratio responsible & $\begin{array}{c}\text { Portion of events } \\
\text { which yielded the } \\
\text { best-performing } \\
\text { portfolio (\%) }\end{array}$ \\
\hline$\overline{\mathrm{VaR}}$ & 18 & $T^{*}$ & 23 & $\mathrm{VaR}$ & 31 & $\mathrm{VaR}$ & 18 \\
\hline CVaR & 12 & SC & 20 & Appraisal & 19 & $T^{*}$ & 10 \\
\hline Calmar & 9 & $\mathrm{~S}^{*}$ & 13 & Sortino & 15 & Appraisal & 9 \\
\hline MVaR & 9 & VaR & 7 & $\mathrm{~T}^{*}$ & 8 & OS & 7 \\
\hline Pain & 9 & Inform & 7 & SC & 4 & Treynor & 6 \\
\hline OS & 9 & $\mathrm{~S}^{* *}$ & 7 & $\mathrm{MVaR}$ & 4 & CVaR & 6 \\
\hline Treynor & 6 & Appraisal & 7 & Inform & 4 & Sortino & 4 \\
\hline Martin & 6 & Calmar & 3 & CVaR & 4 & Calmar & 4 \\
\hline Kappa 3 & 6 & OS & 3 & $\mathrm{~S}^{* *}$ & 4 & MVaR & 4 \\
\hline Burke & 3 & Sharpe & 0 & Treynor & 0 & Inform & 4 \\
\hline Appraisal & 3 & Burke & 0 & Calmar & 0 & Sterling & 3 \\
\hline Sharpe & 0 & Sterling & 0 & Burke & 0 & Pain & 3 \\
\hline Sortino & 0 & $M^{2}$ & 0 & Sterling & 0 & $\mathrm{~S} * *$ & 3 \\
\hline$M^{2}$ & 0 & Martin & 0 & $M^{2}$ & 0 & Martin & 2 \\
\hline SC & 0 & $M V a R$ & 0 & Martin & 0 & Kappa 3 & 2 \\
\hline Israelsen & 0 & Kappa 3 & 0 & Kappa 3 & 0 & Burke & 1 \\
\hline$P W$ & 0 & Israelsen & 0 & Israelsen & 0 & Sharpe & 0 \\
\hline S-Calmar & 0 & Pain & 0 & Pain & 0 & $M^{2}$ & 0 \\
\hline$S^{*}$ & 0 & $P W$ & 0 & $P W$ & 0 & Israelsen & 0 \\
\hline$S^{* *}$ & 0 & S-Calmar & 0 & S-Calmar & 0 & $P W$ & 0 \\
\hline$T^{*}$ & 0 & CVaR & 0 & $S^{*}$ & 0 & S-Calmar & 0 \\
\hline$T^{* *}$ & 0 & $T^{* *}$ & 0 & $T^{* *}$ & 0 & $T^{* *}$ & 0 \\
\hline
\end{tabular}

Sharpe, traditional Sharpe ratio; Treynor, traditional Treynor ratio; $\mathrm{S}^{*}$, scaled Sharpe ratio $1 ; \mathrm{S}^{* *}$, scaled Sharpe ratio 2; SC, serial correlation-adjusted Sharpe ratio; $\mathrm{T}^{*}$, scaled Treynor ratio 1 ; $\mathrm{T}^{* *}$, scaled Treynor ratio 2; Israelson, Israelson's modified Sharpe ratio; Appraisal, modified Appraisal ratio; VaR, value-at-risk Sharpe ratio; MVaR, modified VaR-Sharpe ratio; PW, Pezier and White's adjusted Sharpe ratio; S-Calmar, Sterling-Calmar ratio; OS, Omega-Sharpe ratio; Inform, modified Information ratio.

and $76.32 \%$ from a one-year momentum investment strategy perspective) with a CVaR and MVaR Sharpe portfolio, which makes sense as CVaR and MVaR have similar fundamental features and are thus deemed less desirable from a portfolio diversification point of view due to their poorer ability to yield top-performing portfolios. Furthermore, the third highest correlation (45\%) with the VaR-Sharpe ratio was with an Omega-Sharpe portfolio in 2009 and with an Appraisal ratio portfolio in 2014 (highest average correlation was $31.73 \%$ and $32.88 \%$ from a five-year momentum investment strategy perspective). Even with some level of correlation with the other competing portfolios, these results still fail to overshadow the contributing ability of the VaR-Sharpe ratio to enhance portfolio diversification and to yield topperforming portfolios. However, inconsistent rankings between the three momentum investment strategies and over the different time periods under evaluation are still evident in Table 7, making it difficult to draw an overall conclusion.

To overcome this drawback, this study evaluated the number of events in which each ratio yielded the best-performing portfolio (derived from both the 50:50 and equally weighted ranking approach), which is summarised in Table 8. From the results reported by Table 8 it is advisable that the traditional Sharpe ratio, the $M^{2}$ measure, Israelsen's modified Sharpe ratio, Pezier and White's adjusted Sharpe ratio, the SterlingCalmar ratio and the $\mathrm{T}^{* *}$ should not be consulted for share selection purposes. None of these ratios was able to yield an outperforming portfolio over the time period under evaluation. However, from a one-year momentum investment strategy perspective the VaR-Sharpe, CVaR-Sharpe, MVaR Sharpe, Calmar and Sterling ratios were the top five bestperforming ratios, which were able to provide a $57 \%$ chance (in-sample ex post) of yielding the top-performing portfolios (see Table 8).

However, according to Figure 1 there is a high average correlation between the $\mathrm{VaR}, \mathrm{CVaR}$ and MVaR Sharpe ratio portfolios $(84.71 \%, 88.09 \%$ and $76.32 \%)$, which suggests that the Omega-Sharpe or Pain ratio must be considered as possible substitutes for the CVaR and MVaR Sharpe ratio portfolios in order to enhance the level of portfolio diversification. Then again, there is also a high average correlation of $81.91 \%$ present between the Omega-Sharpe and Pain ratio portfolios, which suggests that the traditional Treynor ratio should also be considered as a possible substitute for the CVaR and MVaR Sharpe ratio portfolios. Based on the results reported by Figure 1, the Pain and Treynor ratio portfolios can be considered as the best alternatives for the CVaR and MVaR Sharpe ratio portfolios, as they exhibited the lowest average correlation with all the top-performing portfolios under consideration. This implies that the revised top five ratios (VaR-Sharpe, Calmar, Sterling, Pain and traditional Treynor ratios) were able to provide a $51 \%$ chance (in-sample ex post) of yielding the top-performing portfolios (see Table 8). On the other hand, from a three-year momentum investment strategy perspective this composition differs slightly, where the $\mathrm{T}^{*}$, 


\begin{tabular}{|c|c|c|c|c|c|}
\hline \multicolumn{6}{|c|}{ ONE-YEAR MOMENTUM INVESTMENT STRATEGY } \\
\hline \multirow{10}{*}{$\begin{array}{l}\text { Average correlation: } \\
\text { 2001-2017 }\end{array}$} & VaR with CVaR & VaR with Calmar & Va R with Sterling & VaR with MVaR & CVaR with Calmar \\
\hline & $84.71 \%$ & $28.68 \%$ & $28.24 \%$ & $76.32 \%$ & $21.18 \%$ \\
\hline & CVaR with Sterling & CVaR with MVaR & Calmar with Sterling & Calmar with MVaR & Sterling with MVaR \\
\hline & $20.59 \%$ & $88.09 \%$ & $88.82 \%$ & $15.15 \%$ & $14.85 \%$ \\
\hline & VaR with Pain & VaR with OS & OS with Pain & CVaR with OS & CVaR with Pain \\
\hline & $27.35 \%$ & $28.68 \%$ & $81.91 \%$ & $20.74 \%$ & $19.85 \%$ \\
\hline & MVaR with Pain & MVaR with OS & VaR with Treynor & CVaR with Treynor & MVaR with Treynor \\
\hline & $14.26 \%$ & $14.71 \%$ & $26.32 \%$ & $28.82 \%$ & $29.85 \%$ \\
\hline & Treynor with OS & Treynor with Pain & Treynor with Calmar & Treynor with Sterling & \\
\hline & $8.38 \%$ & $7.94 \%$ & $8.09 \%$ & $7.50 \%$ & \\
\hline \multicolumn{6}{|c|}{ THREE-YEARS MOMENTUM INVESTMENT STRATEGY } \\
\hline \multirow{4}{*}{$\begin{array}{l}\text { Average correlation: } \\
\text { 2003-2017 }\end{array}$} & $\mathrm{T}^{*}$ with SC & $\mathrm{T}^{*}$ with $\mathrm{S}^{*}$ & $\mathrm{~T}^{*}$ with Treynor & $\mathrm{T}^{*}$ with VaR & SC with S* \\
\hline & $0.00 \%$ & $12.00 \%$ & $14.67 \%$ & $19.67 \%$ & $5.00 \%$ \\
\hline & SC with Treynor & SC with VaR & $\mathrm{S}^{*}$ with Treynor & $\mathrm{S}^{*}$ with $\mathrm{VaR}$ & Treynor with VaR \\
\hline & $7.33 \%$ & $28.00 \%$ & $10.83 \%$ & $1.83 \%$ & $26.00 \%$ \\
\hline \multicolumn{6}{|c|}{ FIVE-YEARS MOMENTUM INVESTMENT STRATEGY } \\
\hline \multirow{10}{*}{$\begin{array}{l}\text { Average correlation: } \\
\text { 2005-2017 }\end{array}$} & VaR with appraisal & VaR with Sortino & VaR with OS & VaR with $T^{*}$ & Appraisal with Sortino \\
\hline & $32.88 \%$ & $25.19 \%$ & $31.73 \%$ & $19.23 \%$ & $0.19 \%$ \\
\hline & Appraisal with OS & Appraisal with $\mathrm{T}^{*}$ & Sortino with OS & Sortino with $\mathrm{T}^{*}$ & OS with $T^{*}$ \\
\hline & $0.19 \%$ & $20.96 \%$ & $78.27 \%$ & $0.00 \%$ & $0.00 \%$ \\
\hline & Sortino with SC & Sortino with Inform & OS with SC & OS with Inform & SC with Inform \\
\hline & $69.81 \%$ & $63.85 \%$ & $78.27 \%$ & $72.50 \%$ & $72.12 \%$ \\
\hline & VaR with $\mathrm{S}^{* *}$ & Appraisal with $\mathrm{S}^{* *}$ & Sortino with $\mathrm{S}^{* *}$ & OS with $\mathrm{S}^{* *}$ & $\mathrm{~T}^{*}$ with $\mathrm{S}^{* *}$ \\
\hline & $22.69 \%$ & $0.19 \%$ & $86.73 \%$ & $73.08 \%$ & $0.00 \%$ \\
\hline & SC with $\mathrm{S}^{* *}$ & MVaR with $\mathrm{S}^{* *}$ & Inform with $S^{* *}$ & CVaR with $\mathrm{S}^{* *}$ & \\
\hline & $78.27 \%$ & $10.38 \%$ & $63.65 \%$ & $16.15 \%$ & \\
\hline \multicolumn{6}{|c|}{ BASED ON TABLE 8'S OVERALL FINDINGS FROM AN ONE-YEAR MOMENTUM INVESTMENT STRATEGY PERSPECTIVE } \\
\hline \multirow{6}{*}{$\begin{array}{l}\text { Average correlation: } \\
\text { 2001-2017 }\end{array}$} & VaR with $T^{*}$ & VaR with appraisal & VaR with SC & VaR with OS & $\mathrm{T}^{*}$ with appraisal \\
\hline & $20.44 \%$ & $33.53 \%$ & $25.74 \%$ & $28.68 \%$ & $21.03 \%$ \\
\hline & $\mathrm{T}^{*}$ with SC & $T^{*}$ with OS & Appraisal with SC & Appraisal with OS & SC with OS \\
\hline & $0.00 \%$ & $0.00 \%$ & $0.00 \%$ & $0.15 \%$ & $79.26 \%$ \\
\hline & SC with Treynor & SC with Sortino & OS with Treynor & OS with Sortino & Treynor with Sortino \\
\hline & $7.94 \%$ & $72.06 \%$ & $8.38 \%$ & $79.85 \%$ & $8.24 \%$ \\
\hline \multicolumn{6}{|c|}{ BASED ON TABLE 8'S OVERALL FINDINGS FROM A THREE-YEARS MOMENTUM INVESTMENT STRATEGY PERSPECTIVE } \\
\hline \multirow{6}{*}{$\begin{array}{l}\text { Average correlation: } \\
\text { 2003-2017 }\end{array}$} & VaR with $T^{*}$ & VaR with appraisal & VaR with SC & VaR with OS & T* with Appraisal \\
\hline & $19.67 \%$ & $33.33 \%$ & $28.00 \%$ & $31.17 \%$ & $20.83 \%$ \\
\hline & $\mathrm{T}^{*}$ with SC & T* with OS & Appraisal with SC & Appraisal with OS & SC with OS \\
\hline & $0.00 \%$ & $0.00 \%$ & $0.00 \%$ & $0.17 \%$ & $78.00 \%$ \\
\hline & SC with Treynor & SC with Sortino & OS with Treynor & OS with Sortino & Treynor with Sortino \\
\hline & $7.33 \%$ & $70.17 \%$ & $7.67 \%$ & $78.17 \%$ & $7.50 \%$ \\
\hline \multicolumn{6}{|c|}{ BASED ON TABLE 8'S OVERALL FINDINGS FROM A FIVE-YEARS MOMENTUM INVESTMENT STRATEGY PERSPECTIVE } \\
\hline Average correlation: & VaR with $\mathrm{T}^{*}$ & VaR with appraisal & VaR with SC & VaR with OS & T* with Appraisal \\
\hline $2005-2017$ & $19.23 \%$ & $32.88 \%$ & $28.65 \%$ & $31.73 \%$ & $20.96 \%$ \\
\hline & $\mathrm{T}^{*}$ with SC & $\mathrm{T}^{*}$ with OS & Appraisal with SC & Appraisal with OS & SC with OS \\
\hline & $0.00 \%$ & $0.00 \%$ & $0.00 \%$ & $0.19 \%$ & $78.27 \%$ \\
\hline & SC with Treynor & SC with Sortino & OS with Treynor & OS with Sortino & Treynor with Sortino \\
\hline & $7.12 \%$ & $69.81 \%$ & $7.50 \%$ & $78.27 \%$ & $6.92 \%$ \\
\hline PERIODS WHERE THE V & ARPE WAS DOMINAI & CORDING TO TABLE 8) & & & \\
\hline ONE-YEAR MOMENTUI & ESTMENT STRATEGY & & & & \\
\hline Correlation: 2007 & VaR with CVaR & VaR with Calmar & VaR with Sterling & VaR with MVaR & CVaR with Calmar \\
\hline & $82.50 \%$ & $40.00 \%$ & $37.50 \%$ & $75.00 \%$ & $35.00 \%$ \\
\hline & CVaR with Sterling & CVaR with MVaR & Calmar with Sterling & Calmar with MVaR & Sterling with MVaR \\
\hline & $35.00 \%$ & $90.00 \%$ & $90.00 \%$ & $27.50 \%$ & $27.50 \%$ \\
\hline THREE-YEARS MOMEN & NVESTMENT STRATEG & & & & \\
\hline Correlation: 2017 & $\mathrm{~T}^{*}$ with SC & $\mathrm{T}^{*}$ with $\mathrm{S}^{*}$ & $\mathrm{~T}^{*}$ with Treynor & $\mathrm{T}^{*}$ with $\mathrm{VaR}$ & SC with S* \\
\hline & $0.00 \%$ & $20.00 \%$ & $25.00 \%$ & $27.50 \%$ & $10.00 \%$ \\
\hline & SC with Treynor & SC with VaR & $\mathrm{S}^{*}$ with Treynor & $\mathrm{S}^{*}$ with $\mathrm{VaR}$ & Treynor with VaR \\
\hline & $5.00 \%$ & $10.00 \%$ & $20.00 \%$ & $2.50 \%$ & $35.00 \%$ \\
\hline FIVE-YEARS MOMENTL & VESTMENT STRATEGY & & & & \\
\hline & VaR with appraisal & VaR with Sortino & VaR with OS & VaR with $T^{*}$ & Appraisal with Sortino \\
\hline Correlation: 2007 & $25.00 \%$ & $15.00 \%$ & $17.50 \%$ & $17.50 \%$ & $0.00 \%$ \\
\hline Correlation: 2009 & $27.50 \%$ & $37.50 \%$ & $45.00 \%$ & $27.50 \%$ & $0.00 \%$ \\
\hline Correlation: 2012 & $35.00 \%$ & $22.50 \%$ & $22.50 \%$ & $15.00 \%$ & $0.00 \%$ \\
\hline Correlation: 2014 & $45.00 \%$ & $7.50 \%$ & $12.50 \%$ & $15.00 \%$ & $0.00 \%$ \\
\hline & Appraisal with OS & Appraisal with $\mathrm{T}^{*}$ & Sortino with OS & Sortino with $T^{*}$ & OS with $\mathrm{T}^{*}$ \\
\hline Correlation: 2007 & $0.00 \%$ & $12.50 \%$ & $87.50 \%$ & $0.00 \%$ & $0.00 \%$ \\
\hline Correlation: 2009 & $0.00 \%$ & $32.50 \%$ & $85.00 \%$ & $0.00 \%$ & $0.00 \%$ \\
\hline Correlation: 2012 & $0.00 \%$ & $22.50 \%$ & $85.00 \%$ & $0.00 \%$ & $0.00 \%$ \\
\hline Correlation: 2014 & $0.00 \%$ & $17.50 \%$ & $75.00 \%$ & $0.00 \%$ & $0.00 \%$ \\
\hline
\end{tabular}

Sharpe, traditional Sharpe ratio; Treynor, traditional Treynor ratio; $\mathrm{S}^{*}$, scaled Sharpe ratio 1; $\mathrm{S}^{* *}$, scaled Sharpe ratio 2; SC, serial correlation-adjusted Sharpe ratio; $T^{*}$, scaled Treynor ratio 1; $T^{* *}$, scaled Treynor ratio 2; Israelson, Israelson's modified Sharpe ratio; Appraisal, modified Appraisal ratio; VaR, value-at-risk Sharpe ratio; MVaR, modified VaR-Sharpe ratio; PW, Pezier and White's adjusted Sharpe ratio; S-Calmar, Sterling-Calmar ratio; OS, Omega-Sharpe ratio; Inform, modified Information ratio.

FIGURE 1: Summary of portfolio correlations. 
the SC-adjusted Sharpe ratio, the $\mathrm{S}^{*}$, the traditional Treynor and the VaR-Sharpe ratios were able to provide an $73 \%$ chance (in-sample ex post) of yielding the top-performing portfolios (see Table 8). This combination of ratios may also ensure some level of diversification, as Figure 1 reports 28\% as the highest average level of correlation between the portfolios under evaluation (was between the VaR-Sharpe and the SC-adjusted Sharpe ratio portfolios). From a five-year momentum investment strategy perspective, the VaR-Sharpe, the Appraisal, the Sortino and the Omega-Sharpe ratios and the $T^{*}$ provided an $81 \%$ change (in-sample ex post) of yielding the top-performing portfolios. However, based on the results reported by Figure 1 there is a high average correlation present between the Sortino, Omega-Sharpe, the SC-adjusted Sharpe, modified information ratios and the $\mathrm{S}^{* *}$ portfolios. This implies that there are no substitutions available (as reported by Table 8 ) with the ability to yield a top-performing portfolio without decreasing the level of portfolio diversification. Therefore, from a five-year momentum investment strategy perspective only the VaR-Sharpe, Appraisal and Sortino ratios should be considered, as these ratios were able to provide a $65 \%$ chance (in-sample ex post) of yielding the top-performing portfolios (see Table 8).

In conclusion, due to the inconsistent results of the top five best-performing ratios between the three momentum investment strategies, an equity portfolio manager's ability to yield the best-performing portfolios will drop to approximately $52 \%$ (in-sample ex post) when consulting only the VaR-Sharpe, the $\mathrm{T}^{*}$, the Appraisal, the SC-adjusted Sharpe and the Omega-Sharpe ratios. However, due to the high average correlation between the SC-adjusted Sharpe, the Omega-Sharpe and the Sortino ratio portfolios (see Figure 1), only the VaR-Sharpe, Appraisal ratios and the $\mathrm{T}^{*}$ ratios should be considered in order to ensure better portfolio diversification and consistency between the three momentum investment strategies under evaluation. However, with these three ratios providing only a $37 \%$ change (in-sample ex post) of yielding the top-performing portfolios, the conclusion can be drawn that both active and passive portfolio managers will have to consult different ratios in conjunction with the VaR-Sharpe ratio in order to ensure better diversified, outperforming equity portfolios.

\section{Conclusion and recommendations}

This study proved that from a risk-adjusted performance perspective it matters which risk denominator is considered to be admissible for the Sharpe ratio framework. Although the standard deviation exhibited poor evidence as a risk denominator, the results suggested that variations of the traditional Sharpe ratio may be more advisable in order to enhance the ability to make more profitable share selections. This study also proved that an equity portfolio of 40 shares can be considered as a viable size, as these portfolios exhibited a low volatility and the ability to outperform most of the buyand-hold proxies (market proxies) from a risk-adjusted returns perspective. However, it will be interesting to see if this number will also be applicable if the long-only equity portfolio is limited to only selected or to fewer sectors. More importantly, the results validated the need to adjust for skewness, kurtosis and SC in a risk-adjusted performance evaluation process. And although the literature highlighted the importance of acknowledging the negative impact of non-normally distributed returns, the results from this study indicated that the attributes of a risk denominator's perspective (like that of the VaR-Sharpe ratio) can overshadow the fundamental shortcoming of assuming the presence of a Gaussian distribution. The study proved that VaR can be considered as the more commendable risk denominators to consult, especially from a one-year and five-year momentum investment strategy perspective. However, the attributes of adjusting for skewness and kurtosis (Gatfaoui 2012) exhibited more promise for a three-year momentum investment strategy approach. It will be interesting to determine if the creditability of $\mathrm{VaR}$ as a risk denominator will decrease over a longer investment horizon. Future studies can also consider the impact of weighting allocations in an equity portfolio and the ideal weighting allocations to consider. The scope of this study also only considered a Sharpe ratio framework, but can be extended to include other ratios and variations thereof. Furthermore, the evidence suggested the presence of timevarying market efficiency, where the level of market efficiency may serve as a valuable asset allocation or selection tool for active portfolio managers. Lastly, the methodology of how to measure total risk must be revised. The results revealed that the standard deviation (total risk) failed as a risk denominator. As it measures only the dispersion of returns around its historical average and penalises positive and negative deviations from the historical average in a similar manner, future studies must consider revising the method of measuring total risk in order to eliminate the 'smoothing' effect caused by the mean, which can lead to underestimation of actual risk if ignored.

\section{Acknowledgements Competing interests}

The author has declared that no competing interests exist.

\section{Author's contributions}

I declare that I am the sole author of this research article.

\section{Funding information}

This research received no specific grant from any funding agency in the public, commercial, or not-for-profit sectors.

\section{Data availability statement}

Data sharing is not applicable to this article as no new data were created or analysed in this study.

\section{Disclaimer}

The views and opinions expressed in this article are those of the author and do not necessarily reflect the official policy or position of any affiliated agency of the author. 


\section{References}

Agarwal, N., 2013, 'Risk weighted alpha index - Analysis of the ASX50 index', Journal of Economics and Financial Studies 1(1), 1-14. https://doi.org/10.18533/jefs.v1i01.34

Agarwal, V. \& Naik, N.Y., 2004, 'Risk and portfolio decisions involving hedge funds', The Review of Financial Studies 17(1), 63-98. https://doi.org/10.1093/rfs/hhg044

Artzner, P., Delbaen, F., Eber, J.M. \& Heath, D., 1997, 'Thinking coherently', Risk 10(68), 68-71.

Artzner, P., Delbaen, F., Eber, J.M. \& Heath, D., 1999, 'Coherent measures of risk' Mathematical Finance 9(3), 203-228. https://doi.org/10.1111/1467-9965.00068

Bacon, C.R., 2008, Practical portfolio performance measurement and attribution, 2nd edn., John Wiley \& Sons, Chichester West

Bawa, V.S., 1975, 'Optimal rules for ordering uncertain prospects', Journal of Financial Economics 2(1), 95-121. https://doi.org/10.1016/0304-405X(75)90025-2

Bekaert, G., Erb, C.B., Harvey, C.R. \& Viskanta, T.E., 1998, 'Distributional characteristics of emerging market returns and asset allocation', The Journal of Portfolio of emerging market returns and asset allocation', The Journal
Management 24(2), 102-116. https://doi.org/10.3905/jpm.24.2.102

Blume, M.E., 1975, 'Betas and their regression tendencies', Journal of Finance 30(3), 785-795. https://doi.org/10.1111/j.1540-6261.1975.tb01850.x

Bonga-Bonga, L., 2012, 'The evolving efficiency of the South African stock exchange', International Business \& Economics Research Journal (IBER) 11(9), 997-1002. https://doi.org/10.19030/iber.v11i9.7183

Bradfield, D., 2015, 'Investment Basics XLVI. On estimating the beta coefficient', Investment Analysts Journal 32(57), 47-53. https://doi.org/10.1080/10293523.20 03.11082448

Burke, G., 1994, 'A sharper Sharpe ratio', Futures 23(3), 56.

Černý, A., 2002, Generalised Sharpe ratios and asset pricing in incomplete markets, viewed 09 September 2019, from http://www3.imperial.ac.uk/portal/pls/ portallive/docs/1/40312.PDF.

Chatterjee, S., Singh, N.P., Goyal, D.P. \& Gupta, N., 2015, Managing in recovering markets, Springer, New Delhi.

Chen, L., He, S. \& Zhang, S., 2011, 'When all risk-adjusted performance measures are the same: In praise of the Sharpe ratio', Quantitative Finance 11(10), 1439-1447. https://doi.org/10.1080/14697680903081881

Committee on the Global Financial System (CGFS), 1999, A review of financial market events in autumn 1998, viewed 10 September 2019, from http://www.bis.org/ publ/cgfs12.pdf.

Committee on the Global Financial System (CGFS), 2000, Tress testing by large financia institutions: Current practice and aggregation issues, viewed 10 September 2019, from http://www.bis.org/publ/cgfs14.pdf.

Darolles, S. \& Gourieroux, C., 2010, 'Conditionally fitted Sharpe performance with an application to hedge fund rating', Journal of Banking and Finance 34(3), 578-593. https://doi.org/10.1016/j.jbankfin.2009.08.025

De Wet, R., Krige, J.D. \& Smit, E.vd M., 2008, 'An investigation into performance rankings of the Omega ratio vs. the Sharpe ratio applied to South African genera equity unit trusts', Journal of Studies in Economics and Econometrics 32(2), 69-83.

Domian, D.L., Louton, D.A. \& Racine, M.D., 2007, 'Diversification in portfolios of individual stocks: 100 stocks are not enough', Financial Review 42(4), 557-570. https://doi.org/10.1111/j.1540-6288.2007.00183.x

Dowd, K., 1999, 'A value at risk approach to risk-return analysis', The Journal of Portfolio Management 25(4), 60-67. https://doi.org/10.3905/jpm.1999.319755

Dowd, K., 2000, 'Adjusting for risk: An improved Sharpe ratio', International Review of Economics and Finance 9(3), 209-222. https://doi.org/10.1016/S1059-0560(00) 00063-0

Eling, M., Farinelli, S., Rossello, D. \& Tibiletti, L., 2010, 'One-size or tailor-made performance ratios for ranking hedge funds?', Journal of Derivatives and Hedge Funds 16(4), 267-277. https://doi.org/10.1057/jdhf.2010.20

Esfahanipour, A. \& Mousavi, S., 2011, 'A genetic programming model to generate riskadjusted technical trading rules in stock markets', Expert Systems with Application 38(7), 8438-8445. https://doi.org/10.1016/j.eswa.2011.01.039

Evans, J.L. \& Archer, S.H., 1968, 'Diversification and the reduction of dispersion: An empirical analysis', Journal of Finance 23(5), 761-767. https://doi.org/10.1111/ j.1540-6261.1968.tb00315.

Fama, E.F., 1965a, 'Portfolio analysis in a stable Paretian Market', Management Science 11(3), 404-419. https://doi.org/10.1287/mnsc.11.3.404

Fama, E.F., 1965b, 'The behavior of stock market prices', Journal of Business 38(1), 34-105. https://doi.org/10.1086/294743

Fama, E.F., 1991, 'Efficient capital markets: II', Journal of Finance 46(5), 1575-1617. https://doi.org/10.1111/j.1540-6261.1991.tb04636.x

Fama, E.F. \& French, K.R., 1992, 'The cross-section of expected stock returns', Journal of Finance 47(2), 427-465. https://doi.org/10.1111/j.1540-6261.1992.tb04398.x

Favre, L. \& Galeano, J-A., 2002, 'Mean-modified value-at-risk optimization with hedge funds', The Journal of Alternative Investments 5(2), 21-25. https://doi.org/ 10.3905/jai.2002.319052

Fishburn, P.C., 1977, 'Mean-risk analysis with risk associated with below-target returns', The American Economic Review 67(2), 116-126.

Fung, W. \& Hsieh, D.A., 1999, 'Is mean-variance analysis applicable to hedge funds?' Economic Letters 62(1), 53-58. https://doi.org/10.1016/S0165-1765(98)00140-2

Gatfaoui, H., 2012, 'A correction for classic performance measures', Chinese Business Review 11(1), 1-28. https://doi.org/10.17265/1537-1506/2012.01.001
Gilli, M. \& Schumann, E., 2011, 'Risk-reward optimisation for long-run investors: An empirical analysis', European Actuarial Journal 1(2), 303-327. https://doi. org/10.1007/s13385-011-0024-2

Goetzmann, W., Ingersoll, J., Spiegel, M.I. \& Welch, I., 2002, Sharpening Sharpe ratios, viewed 09 September 2019, from http://www.edge-fund.com/Goetzmannetal2004.pdf. https://doi.org/10.3386/w9116.

Grandes, M. \& Pinaud, N., 2004, Which policies can reduce the cost of capital in Southern Africa?, viewed 13 September 2019, from http://search.oecd.org/ countries/swaziland/33722694.pdf.

Gregoriou, G.N. \&Gueyie, J.P., 2003, 'Risk-adjusted performance of funds of hedge funds using a modified Sharpe ratio', The Journal of Wealth Management 6(3), 77-83. https://doi.org/10.3905/jwm.2003.442378

Grinold, R.C., 1989, 'The fundamental law of active management', The Journal of Portfolio Management 15(3), 30-37. https://doi.org/10.3905/jpm.1989.409211

Gul, F., 1991, 'A theory of disappointment aversion', Econometrica 59(3), 667-686. https://doi.org/10.2307/2938223

Harding, D., 2002, A critique of the Sharpe Ratio, viewed 12 August 2019, from http:// michaelcovel.com/pdfs/Hard02.pdf.

Harlow, W.V., 1991, 'Asset allocation in a downside-risk framework', Financial Analyst Journal 47(5), 28-40. https://doi.org/10.2469/faj.v47.n5.28

Heymans, A. \& Santana, L., 2018, 'How efficient is the Johannesburg Stock Exchange really?', South African Journal of Economic and Management Sciences 21(1) 1-14. https://doi.org/10.4102/sajems.v21i1.1968

IRESS, 2019, Date source, viewed 20 August 2019, from http://secure.mcgbfa.com/.

Israelsen, C., 2005, 'A refinement to the Sharpe ratio and information ratio', Journal of Asset Management 5(6), 423-427. https://doi.org/10.1057/palgrave.jam. 2240158

Jegadeesh, N. \& Titman, S., 1993, 'Returns to buying winners and selling losers: Implications for stock market efficiency', Journal of Finance 48(1), 65-91. https:// doi.org/10.1111/j.1540-6261.1993.tb04702.x

Kahneman, D. \& Tversky, A., 1979, 'Prospect theory: An analysis of decision unde risk', Econometrica 47(2), 263-292. https://doi.org/10.2307/1914185

Kaplan, P.D. \& Knowles, J.A., 2004, Kappa: A generalized downside risk-adjusted performance measure, Morningstar Associates and York Hedge Fund Strategies, New York.

Kat, H.M., 2003. '10 Things investors should know about hedge funds', The Journal of Wealth Management 5(4), 72-81. https://doi.org/10.3905/jwm.2003.320466

Keating, C. \& Shadwick, W.F., 2002, 'A universal performance measure', Journal of Performance Measurement 6(3), 59-84.

Kestner, L., 1996, 'Getting a handle on true performance', Futures 25(1), 44-46.

Kolbadi, P. \& Ahmadinia, H., 2011, 'Examining Sharp, Sortino and Sterling ratios in portfolio management, evidence from Tehran Stock Exchange', Internationa Journal of Business and Management 6(4), 222-236. https://doi.org/10.5539/ ijbm.v6n4p222

Lamm, R.M., 2003, 'Asymmetric returns and optimal hedge fund portfolios', Journal of Alternative Investments 6(2), 9-21. https://doi.org/10.3905/jai.2003.319088

Lhabitant, F., 2004, Hedge funds: Quantitative insight, John Wiley and Sons, Haboken, NY.

Lo, A.W., 2002, 'The statistics of Sharpe ratios', Financial Analysts Journal 58(4), 36-52. https://doi.org/10.2469/faj.v58.n4.2453

Mandelbrot, B., 1963, 'The variation of certain speculative prices', Journal of Business 36(4), 394-419. https://doi.org/10.1086/294632

Markowitz, H.M., 1952, 'Portfolio selection', Journal of Finance 7(1), 77-91. https:// doi.org/10.1111/j.1540-6261.1952.tb01525.x

Markowitz, H.M., 1959, Portfolio selection: Efficient diversification of investment, John Wiley and Sons, New York, NY.

Martin, P. \& Mccann, B., 1989, The investor's quide to fidelity funds: Winning strategies for mutual fund investors, John Wiley and Sons, Chichester.

Martin, P. \& McCann, B., 1998, The investor's guide to fidelity funds: Winning strategies for mutual fund investing, 2nd edn., Venture Catalyst Inc., Redmond.

Mcmillan, D.G. \& Thupayagale, P., 2008, 'Efficiency of the South African equity market', Applied Financial Economics Letters 4(5), 327-330. https://doi.org/10.1080/ 1744654070172071

Mcleod, W. \& Van Vuuren, G., 2004, 'Interpreting the Sharpe ratio when excess returns are negative', Investment Analysts Journal 33(59), 15-20. https://doi.org/ 10.1080/10293523.2004.11082455

Meyer, J., 1987, 'Two moment decision model and expected utility maximization', American Economic Review 77(3), 421-430.

Meyer, J. \& Rasche, R.H., 1992, 'Sufficient conditions for expected utility to imply mean-standard deviation rankings: Empirical evidence concerning the location and scale condition', The Economic Journal 102(410), 91-106. https://doi. org/10.2307/2234854

Modigliani, F. \& Modigliani, L., 1997, 'Risk-adjusted performance', The Journal of Portfolio Management 23(2), 45-54. https://doi.org/10.3905/jpm.23.2.45

Newbould, G.D. \& Poon, P.S., 1993, 'The minimum number of stocks needed for diversification', Financial Practice and Education 3(2), 85-87.

Nielsen, L.T. \&Vassalou, M., 2004, 'Sharpe ratios and alphas in continuous time', Journal of Financial and Quantitative Analysis 39(1), 103-114. https://doi. org/10.1017/S0022109000003902 
Pezier, J. \& White, A., 2006, The relative merits of investable hedge fund indices and of funds of hedge funds in optimal passive portfolios, viewed 08 August 2019, from http://www.icmacentre.ac.uk/pdf/discussion/DP2006-10.pdf.

Roy, A.D., 1952, 'Safety first and the holding of assets', Econometrica 20(3), 431-449. https://doi.org/10.2307/1907413

Sarykalin, S., Serraino, G. \& Uryasev, S., 2008, 'Value-at-risk vs. conditional value-atrisk in risk management and optimization', in Z.L. Chen \& S. Raghavan (eds.), Tutorials in operations research: State-of-the-art decision-making tools in the information-intensive age, pp. 270-294, INFORMS, Hanover, NH. https://doi. information-intensive age, $\mathrm{p}$ org

Schuhmacher, F. \&Eling, M, 2011, 'Sufficient conditions for expected utility to imply drawdown-based performance measures', Journal of Banking and Finance 35(9), 2311-2318. https://doi.org/10.1016/j.jbankfin.2011.01.031

Schuhmacher, F. \& Eling, M., 2012, 'A decision-theoretic foundation for reward-to-risk performance measures', Journal of Banking and Finance 36(7), 2077-2082. https://doi.org/10.1016/j.jbankfin.2012.03.013

Sharpe, W.F., 1966, 'Mutual fund performance', Journal of Business 39(1), 119-138. https://doi.org/10.1086/294846

Sharpe, W.F., 1971, 'Mean-absolute-deviation characteristic lines for securities and portfolios', Management Sciences 18(2), B1-B13. https://doi.org/10.1287/ mnsc.18.2.B1

Sharpe, W.F., 1994, 'The Sharpe ratio', The Journal of Portfolio Management 21(1), 49-58. https://doi.org/10.3905/jpm.1994.409501

Sinn, H.W., 1983, Economic decisions under uncertainty, Physica-Verlag, Heidelberg.

Sortino, F.A. \& Van Der Meer, R., 1991, 'Downside risk', The Journal of Portfolio Management 17(4), 27-31. https://doi.org/10.3905/jpm.1991.409343

South African Reserve Bank (SARB), 2019, Date source, viewed 08 August 2019, from http://www.resbank.co.za/Research/Statistics/Pages/OnlineDownloadFacility. aspx.

Statman, M., 1987, 'How many stocks make a diversified portfolio?', Journal of Financial and Quantitative Analysis 22(3), 353-363. https://doi.org/10.2307/ 2330969

Tang, G.Y.N., 2004, 'How efficient is naive portfolio diversification? An educational note', Omega 32(2), 155-160. https://doi.org/10.1016/j.omega.2003.10.002

Tasche, D., 2002, 'Expected shortfall and beyond', Journal of Banking and Finance 26(7), 1519-1533. https://doi.org/10.1016/S0378-4266(02)00272-8
Terhaar, K., Staub, R. \& Singer, B., 2003, 'Appropriate policy allocation for alternative investments: A factor approach and simulation techniques', The Journal of Portfolio Management 29(3), 101-110. https://doi.org/10.3905/jpm.2003. Portfolio

Treynor, J.L., 1965, 'How to rate management investment funds', Harvard Business Review 43(1), 63-75.

Treynor, J.L. \& Black, F., 1973, 'How to use security analysis to improve portfolio selection', Journal of Business 46(1), 66-88. https://doi.org/10.1086/295508

Van Dyk, F., Van Vuuren, G. \& Heymans, A., 2014, 'Hedge fund performance using scaled Sharpe and Treynor measures', International Business and Economic Research Journal 13(6), 1261-1300. https://doi.org/10.19030/iber.v13i6.8920

Van Heerden, C., 2015, 'The influence of higher moments and non-normality on the Sharpe ratio: A South African perspective', Journal of Applied Business Research 31(1), 197-220. https://doi.org/10.19030/jabr.v31i1.9001

Van Heerden, C., 2016, 'The eminence of risk-free rates in portfolio management: A South African perspective', The Journal of Applied Business Research 32(2), 569-596. https://doi.org/10.19030/jabr.v32i2.9597

Van Heerden, C. \& Coetzee, J., 2019, 'Re-examining the ability to explain future South African banking share returns: A data envelopment analysis approach', South African Journal of Economic and Management Sciences 22(1), 1-18. https://doi. org/10.4102/sajems.v22i1.2852

Wise, J., 1966, Linear estimators for linear regression systems having infinite residual variances. Informal discussion paper, viewed 12 August 2019, from http://north worldcat.org/title/linear-estimators-for-linear-regression-systems-havinginfinite-residual-variances/oclc/22133136.

Yamai, Y. \& Yoshiba, T, 2002, 'Comparative analyses of expected shortfall and value-atrisk: Their estimation error, decomposition, and optimization', Monetary and Economic Studies 20(1), 87-121.

Young, T.W., 1991, 'Calmar ratio: A smoother tool', Futures 20(1), 40.

Zakamouline, V. \& Koekebakker, S., 2009, 'Portfolio performance evaluation with generalized Sharpe ratios: Beyond the mean and variance', Journal of Banking and Finance 33(7), 1242-1254. https://doi.org/10.1016/j.jbankfin.2009. 01.005

Zephyr Associates, 2006, Pain ratio, viewed 19 July 2019, from http://www. styleadvisor.com/content/pain-ratio.

Ziemba, W.T., 2005, 'The symmetric downside-risk Sharpe ratio', The Journal of Portfolio Management 32(1), 108-122. https://doi.org/10.3905/jpm.2005.599515 